\title{
Sitagliptin Attenuates Porphyromonas Gingivalis Virulence and Inflammatory Response in Macrophage on Titanium
}

\author{
Weilong Tang \\ Wuhan University \\ Minquan Du \\ Wuhan University
}

Shuang Zhang

Wuhan University

Han Jiang ( $\sim$ jianghan@whu.edu.cn )

Wuhan University

\section{Research Article}

Keywords: sitagliptin, porphyromonas gingivalis, macrophage, titanium, peri-implantitis

Posted Date: December 9th, 2021

DOI: https://doi.org/10.21203/rs.3.rs-1091111/v1

License: (9) This work is licensed under a Creative Commons Attribution 4.0 International License. Read Full License 
1 Sitagliptin Attenuates Porphyromonas Gingivalis Virulence and Inflammatory Response in Macrophage on Titanium

Weilong Tang ${ }^{1}$, Minquan Du ${ }^{1}$, Shuang Zhang ${ }^{1 *}$, Han Jiang ${ }^{1 *}$

Shuang Zhang and Han Jiang share the correspondence authors and both contributed equally to this study.

\section{*Correspondence:}

Shuang Zhang

School and Hospital of Stomatology, Wuhan University, 237 Luoyu Road, Wuhan 430079, China. E-mail: zhangshuanggg@whu.edu.cn; Fax: +86 27 87686227; Tel: $+862787686227$

Han Jiang

School and Hospital of Stomatology, Wuhan University, 237 Luoyu Road, Wuhan 430079, China. E-mail:jianghan@whu.edu.cn Fax: +86 27 87686227; Tel: +86 27 87686227 


\begin{abstract}
Background: In peri-implantitis, porphyromonas gingivalis and macrophage play central roles. The aim of this study was to detect the attenuating effect of an anti-diabetic drug sitagliptin on porphyromonas gingivalis virulence and inflammatory response in macrophage on titanium discs.

Materials and methods: Porphyromonas gingivalis and macrophage were cultured on titanium discs. Antibacterial and antibiofilm activities of sitagliptin were assessed and the morphology of porphyromonas gingivalis were observed by SEM. Bacterial early adhesion, aggregation, hemagglutination, hemolysis and porphyromonas gingivalis virulence factors mRNA expression were assessed to preliminarily investigate the mechanisms of action. Flow cytometry assay, qRT-PCR and Western Blot were used to assess the anti-inflammatory effect of sitagliptin on porphyromonas gingivalis lipopolysaccharide-stimulated macrophage.

Results: The present study demonstrated the inhibiting effect of sitagliptin on the growth, biofilm, phenotypic behavior and virulence factors of porphyromonas gingivalis and the protective effect on the porphyromonas gingivalis lipopolysaccharide-induced polarization in macrophage. And we also confirmed the anti-inflammatory effect of sitagliptin on the secretion of inflammation-related factors in macrophage by inhibiting the MAPK and AKT signaling pathways.

Conclusions: Sitagliptin possesses the attenuating effect on porphyromonas gingivalis virulence and inflammatory response in porphyromonas gingivalis lipopolysaccharide-stimulated macrophage on titanium.
\end{abstract}

Keywords: sitagliptin, porphyromonas gingivalis, macrophage, titanium, peri-implantitis. 


\section{Background}

Based on the osseointegration theory put forward by Brånemark [1, 2], dental implantation has become a widely accepted and implemented treatment for tooth loss. Although reported high long-term survival rates were up to $96.1 \%$ after 10 years and $83.8 \%$ after 25 years [3, 4], implant failure may still occur. And in implant failure, peri-implantitis characterized by plaque-induced inflammation of the oral tissue surrounding the implants is a crucial element $[5,6]$. Similar to the pathogenesis of periodontitis, peri-implantitis is the result of a continuum of microbial pressure, inflammation and tissue destruction [6].

In regard to microbial pressure, porphyromonas gingivalis (P. gingivalis; Pg), the most representative strain involves in severe human periodontitis, appears in large numbers on titanium implants and produces several virulence factors in the process of peri-implantitis [7, 8]. Thus, attenuating virulence of $\mathrm{P}$. gingivalis is a clinically valuable strategy to impede the progression of peri-implantitis.

As for plaque-induced inflammation, it was reported that a large number of inflammatory cells, particularly macrophages infiltrated peri-implantitis lesions [9]. Macrophage is regarded as a central player in immune-inflammatory processes due to its phagocytic capacity and high cellular plasticity [10] and its function and phenotype polarization is the focus of research on the inflammatory conditions contributing to diseases such as periodontitis, diabetes and peri-implantitis [11-13]. Stimulated by bacteria sub-products like lipopolysaccharides (LPS), macrophages present a M1 phenotype involving in pro-inflammatory reactions (e.g. secreting IL-1ß, IL-6, IL-8), while macrophages activated by alternative ways present a M2 phenotype and are associated with anti-inflammatory reactions[10]. Hence, a medication modulating M1/M2 status plays a significant role in attenuating inflammatory reaction of macrophage and counteracting the pathogenesis and destructive mechanisms of peri-implant diseases.

Sitagliptin, the first dipeptidyl-peptidase (DPP)-4 inhibitor, was approved and widely used as a glucose-lowering intervention for patients with type 2 diabetes [14]. Recently, more studies have reported the potential therapeutic effect of sitagliptin on other diseases including epilepsy, genital infections and COVID-19 [15-17]. Since studies have shown that DPP-4 is also expressed on the surface of macrophages [18, 19], sitagliptin may have an influence on the biological function of macrophages, thus regulating the inflammatory diseases in which macrophage involved.

P. gingivalis DPP-4 exhibits the similar substrate specificity to its human counterpart, hence sitagliptin could inhibit P. gingivalis DPP-4 as well [20-22]. And due to the suppressing effect of sitagliptin on quorum-sensing (QS) and X-prolyl dipeptidyl aminopeptidase which is similar to DPP-4, recent studies have determined that sitagliptin could attenuate the streptococcus mutans [23], serratia marcescens [24] and pseudomonas aeruginosa virulence [25]. However, to our knowledge, there is few study on the effects of sitagliptin on P. gingivalis in which QS and X-prolyl dipeptidyl aminopeptidase also play significant role.

Hence, it is reasonable to speculate that sitagliptin can be used as a potential agent to 
control peri-implant inflammation by inhibting $\mathrm{P}$. gingivalis virulence and $\mathrm{P}$. gingivalis LPS-induced inflammation of macrophage. To verify our hypothesis, the aim of this study was to detect the effect of sitagliptin on the virulence of P. gingivalis, the P. gingivalis LPS-induced polarization and inflammation related factors secretion of macrophage and the possible mechanism.

\section{Materials and Methods}

\section{Titanium disc preparation}

Commercial pure titanium discs (TA1 grade according to ISO 5832-2:1993) of 34mm and $15 \mathrm{~mm}$ in diameter, and $1 \mathrm{~mm}$ in thickness were purchased from BaoJiXinNuo Ltd. (Shanxi, China). To simulate practical roughness, discs were sandblasted and acid-etched (SLA) as previously described [26]. Before cell or bacteria culturing, a SLA disc was sterilized and then placed into each well of a flat-bottomed 24-well or 6-well microplate.

\section{Bacteria and culture conditions}

Porphyromonas gingivalis ATCC 33277 was used in this present study and cultured in Tryptic Soy Broth (TSB; BD, NJ, USA) with $5 \mathrm{mg} / \mathrm{ml}$ of yeast extract (Oxoid, Hampshire, UK), $5 \mu \mathrm{g} / \mathrm{ml}$ of hemin (Solarbio, Beijing, China), $1 \mu \mathrm{g} / \mathrm{ml}$ of Vitamin $\mathrm{K}$ (Alaadin, Shanghai, China) and $0.5 \mathrm{mg} / \mathrm{ml}$ of L-cysteine hydrochloride (Alaadin, Shanghai, China) at $37^{\circ} \mathrm{C}$ under anaerobic conditions.

\section{Antibacterial activities assay}

P. gingivalis suspension was adjusted in TSB containing $1 \times 10^{7}$ colony-forming units $(\mathrm{CFU}) / \mathrm{mL}$ with Sitagliptin (Topscience, Shanghai, China) prepared ranging from 2500 to $25 \mu \mathrm{g} / \mathrm{ml}$ or TSB as control. $1 \mathrm{ml}$ of the suspension was added in each well of a 24-well microplate to cover the SLA disc, and incubated for $48 \mathrm{~h}$. The MIC referred to the lowest concentration of sitagliptin inhibiting microorganism growth.

After incubation, $10 \mu \mathrm{l}$ suspension from each well was transferred to the Columbia blood plate medium (Luqiao Technology, Zhengzhou, China). The MBC was the lowest concentration of sitagliptin at which no colony occurs after incubation for 3-5 days under anaerobic conditions[27].

\section{Antibiofilm activities assay}

\subsection{Biofilm formation assay}

P. gingivalis biofilm formation was assayed by the crystal violet staining method [28]. P. gingivalis suspension $\left(1 \times 10^{7} \mathrm{CFU} / \mathrm{mL}\right)$ with sitagliptin of different concentration was added in a 24-well microplate. After $48 \mathrm{~h}$ of incubating, the cultures were gently discarded and the adherent biofilms on the SLA discs were rinsed for three times with phosphate buffered saline (PBS). Then, the adherent biofilms were incubated with anhydrous methanol for $15 \mathrm{~min}$ and then stained with $0.1 \%(\mathrm{w} / \mathrm{v})$ crystal violet $(\mathrm{CV})$ 
for $15 \mathrm{~min}$. After the excess $\mathrm{CV}$ was washed away with double distilled water, anhydrous methanol was added to dissolve the CV stained on biofilms. Finally, the anhydrous methanol was transferred to a 96-well microplate and the optical density (OD) values at the wavelength of $560 \mathrm{~nm}$ were recorded by using microplate reader. The minimum biofilm inhibition concentration $\left(\mathrm{MBIC}_{50}\right)$ was defined as the lowest concentration of sitagliptin that resulted in at least $50 \%$ inhibition of the biofilm formation compared with the control.

\subsection{Biofilm reduction assay}

The effect of sitagliptin on $\mathrm{P}$. gingivalis biofilm reduction was also assayed by $\mathrm{CV}$ staining [29]. To form mature biofilms, P. gingivalis suspension $\left(1 \times 10^{7} \mathrm{CFU} / \mathrm{mL}\right)$ was grown in a $24-w e l l$ microplate for $48 \mathrm{~h}$.

After removing the supernatant, the non-adherent bacteria were gently rinsed off with PBS. Then, TSB medium with sitagliptin of different concentration was added into the microplate for $24 \mathrm{~h}$ anaerobically. The biomass and metabolic activity were determined with the $\mathrm{CV}$ assay as described above. Minimum biofilm reduction concentration $\left(\mathrm{MBRC}_{50}\right)$ was defined as the lowest concentration of sitagliptin required to eradicate the preformed biofilm by at least $50 \%$.

\subsection{Biofilm viability assay}

The effects of sigtaliptin on P. gingivalis biofilm viability were tested with a CCK8 kit (Dojindo, Shanghai, China). First, the biofilm was treated in the same way as in the biofilm reduction assay. Subsequently, $1 \mathrm{~mL}$ TSB medium mixed with 10\% CCK-8 reagent was added into each well of 24-well microplate. After incubation of $2 \mathrm{~h}$, supernatant was transferred to a 96-well microplate for analysis at $450 \mathrm{~nm}(630 \mathrm{~nm}$ as reference).The sessile MIC $\left(\mathrm{SMIC}_{50}\right)$ referred to the lowest drug concentration resulting in at least $50 \%$ reduction compared with that of control.

\section{Morphological observation by scanning electron microscopy (SEM)}

P. gingivalis suspension $\left(1 \times 10^{7} \mathrm{CFU} / \mathrm{mL}\right)$ with TSB and sitagliptin dilution of MIC and $\mathrm{MBC}$ was added in 24-well microplate. After incubation of $48 \mathrm{~h}$, the SLA discs were washed with PBS three times and then fixed with $2.5 \%(\mathrm{v} / \mathrm{v})$ glutaraldehyde for $5 \mathrm{~h}$. The discs were washed with PBS, followed by a dehydration with a serial concentration (75, 80, 90, 95 and 100\% ) of ethanol solutions. Samples were then critical-point-dried and coated with gold. After that, P. gingivalis was photographed by SEM.

\section{Effect of sitagliptin at sub-MIC on P. gingivalis virulence 6.1 bacterial growth assay}

According to Abbas and Hegazy [24], the effect of sitagliptin at sub-MIC on the growth of P. gingivalis was detected. After incubation with or without sitagliptin at sub-MIC as described above, $100 \mu \mathrm{l}$ suspension from each well was transferred to a 96-well microplate and then measured at the wavelength of $600 \mathrm{~nm}$. 


\subsection{Early adhesion to titanium}

The SLA discs were immersed in P. gingivalis suspension of $1 \times 10^{8} \mathrm{CFU} / \mathrm{mL}$ with sitagliptin of sub-MIC and incubated for $4 \mathrm{~h}$ anaerobically. To visually observe and quantificationally measure the P. gingivalis early adhered to the SLA discs, SEM and CCK8 method were used as described above.

\subsection{Bacterial aggregation}

As described previously [30], P. gingivalis aggregation was measured with minor modifications. P. gingivalis were incubated with sitagliptin of sub-MIC overnight anaerobically. Harvested by centrifugation, the bacteria were rinsed and re-suspended with $\mathrm{PBS}$ to $\mathrm{OD}_{600}=1.0$. The suspension was monitored for autoaggregation (decrease in absorbance as the cells clumped) after $3 \mathrm{~h}$.

\subsection{Bacterial hemagglutination}

Hemagglutination assay was performed as described previously [30, 31], with modifications. $24 \mathrm{~h}$ cultures of $\mathrm{P}$. gingivalis with sitagliptin of sub-MIC were harvested, centrifuged, and re-suspended. The bacteria suspension was serially diluted (1:2 to $1: 128$ ) in PBS and mixed with sitagliptin of sub-MIC. Then $100 \mu \mathrm{L}$ of the mixture was added into each well of a 96-well plate. After the sheep defibrinated blood (Solarbio, Beijing, China) was centrifugated and rinsed with PBS three times, the erythrocytes were harvested and diluted to $5 \%(\mathrm{v} / \mathrm{v})$. Subsequently, $100 \mu \mathrm{L}$ of sheep erythrocytes suspension were added to the bacteria suspension and incubated at room temperature for $3 \mathrm{~h}$. Finally, hemagglutination was detected visibly.

\subsection{Bacterial hemolysis}

The quantification of bacterial hemolysis was performed as described [32] with modification. Overnight cultures of $\mathrm{P}$. gingivalis were adjusted to $\mathrm{OD}_{600}=1.5$. Sheep erythrocytes were washed until no hemoglobin can be detected visibly in the supernatant. Then the sheep erythrocytes were diluted to $2 \% \quad(\mathrm{v} / \mathrm{v})$ and mixed with an equal volume of bacteria suspension with or without sitagliptin. Control samples were incubated with PBS (negative control) or 1\% triton X-100 (positive control). The mixture was added to cover the SLA disc in a 24 -well plate and incubated at $37^{\circ} \mathrm{C}$ for $18 \mathrm{~h}$. The hemolysis was quantified at wavelength of $540 \mathrm{~nm}$.

\subsection{Effect on the expressions of virulence factors}

To determine the effect of sitagliptin of sub-MIC on the expression of P. gingivalis virulence factors, reverse transcription-quantitative polymerase chain reaction (RT-PCR) was performed as follows. The sitagliptin of sub-MIC was added to bacterial cultures $\left(\mathrm{OD}_{600}=0.8\right)$ prior to anaerobic culturing at $37^{\circ} \mathrm{C}$ for $24 \mathrm{~h}$. Then the total RNA of bacteria was extracted by Trizol reagent (Takara, Dalian, China), followed by measurement of RNA concentration by Nanodrop and reverse 
transcription by PrimeScript RT reagent Kit (Takara, Dalian, China). Finally, PCR was performed with $10 \mu \mathrm{L}$ of a mixture containing $2 \mu \mathrm{L}$ of the cDNA template, $2 \mu \mathrm{L}$ of double distilled water , $5 \mu \mathrm{L}$ of SYBR Green Realtime PCR Master Mix (Toyobo, Shanghai, China) and $0.5 \mu \mathrm{L}$ of each primer, under the following conditions: 2 min at $95{ }^{\circ} \mathrm{C}, 5 \mathrm{~s}$ at $95{ }^{\circ} \mathrm{C}$ and $30 \mathrm{~s}$ at $60{ }^{\circ} \mathrm{C}$ for 40 cycles, $5 \mathrm{~s}$ at $95{ }^{\circ} \mathrm{C}, 5 \mathrm{~s}$ at $65{ }^{\circ} \mathrm{C}, 5 \mathrm{~s}$ at $95^{\circ} \mathrm{C}$. The forward and reverse primer sequences are shown in Table1.

\section{Cell culture}

Obtained from the China Center for Type Culture Collection, Wuhan, China, RAW 264.7 was used in this present study and cultured in high glucose DMEM (Hyclone, USA) containing 10\% fetal bovine serum (FBS; Gibco, USA ) at $37^{\circ} \mathrm{C}$ in a $5 \% \mathrm{CO}_{2}$ incubator (Thermo, USA). For different experiments, RAW 264.7 was cultured in a 24-well or 6-well plate covering the SLA discs.

\section{Cytotoxicity Assay}

RAW 264.7 was seeded in a 24-well plate at a density of $1 \times 10^{5}$ cells/well and then cultured for $24 \mathrm{~h}$, with sitagliptin or sitagliptin $+5 \mu \mathrm{g} / \mathrm{ml}$ Pg-LPS (Invivogen, Shanghai, China). Then the cell viability was determined by using CCK8 kit as described above.

\section{Flow cytometry assay}

Differently treated RAW264.7 cells (10\%/sample) were washed twice in PBS containing $2 \%$ FBS and then incubated with fluorescently labeled antibodies CD86-APC ( biolegend, USA) for $30 \mathrm{~min}$ at $4^{\circ} \mathrm{C}$. Subsequently, samples were washed twice and fixed and permeated with Fix/Perm Buffer ( BD Pharmingen, USA). After that, cells were incubated with CD206-PerCP/Cy5.5 ( biolegend, USA) as described above. Cells were washed twice prior to flow cytometry.

\section{RT-PCR assay}

RT-PCR assay was used to analyse gene expression at mRNA level. Differently treated cells were harvested and rinsed twice with PBS. Then the RNA isolation and qRT-PCR assay was performed as described above. The forward and reverse primer sequences are shown in Table2.

\section{ELISA assays}

For cytokine gene-expression analysis at protein level, ELISA kit (Neobioscience, Shenzhen, China) were used to measure IL-1and IL-6 in the supernatant following the manufacturer's protocol.

\section{Western Blot Analysis}

Differently treated cells were harvested, washed twice with cold PBS and then lysed 
with RIPA buffer (Servicebio, Wuhan, China) on ice. After sonication and centrifugation, the protein concentrations of samples were determined with BCA protein quantitative detection kit (Beyotime, Shanghai, China) and normalized. Subsequently, denatured lysate proteins were separated by $10 \%$ SDS-PAGE and transferred to polyvinylidene difluoride membranes. The membranes were then blocked and incubated with primary antibodies (Servicebio) overnight at $4{ }^{\circ} \mathrm{C}$, prior to incubating with secondary antibody (Servicebio) and visualization reagent. The chemiluminescence was detected with Image Studio System (LICOR, Lincoln, NE, USA). Immunoreactive bands were quantified with Image J analysis.

\section{Statistical Analysis}

GraphPad Prism 8.0.1 software was used for statistical analyses. All results are presented as means \pm standard deviation (SD). Ordinary one-way analysis of variance (ANOVA) was used to compare the differences between parameters in each group, and $\mathrm{p}<0.05$ were considered significant.

\section{Results}

\section{The antimicrobial assay of sitagliptin against $P$. gingivalis}

The activity of sitagliptin against planktonic P. gingivalis and P. gingivalis biofilm was determined by broth microdilution method. Results of the susceptibility assay of planktonic P. gingivalis to sitagliptin are shown in Table3. The MIC and the MBC values of sitagliptin were 250 and $2500 \mu \mathrm{g} / \mathrm{ml}$, respectively.

As shown in Figure1 (A-C) and Table 3, sitagliptin showed its effect on the formation, reduction and viability of $\mathrm{P}$. gingivalis biofilm. The $\mathrm{MBIC}_{50}, \mathrm{MBRC}_{50}$ and $\mathrm{SMIC}_{50}$ of sitagliptin was 500, 2000 and $1000 \mu \mathrm{g} / \mathrm{ml}$, respectively.

To explore the antibacterial mechanism of sitagliptin against $\mathrm{P}$. gingivalis, the morphological changes of P. gingivalis treated with sitagliptin on SLA discs was observed by SEM. In the control group, the cells observed were plump and cell membranes remained clearly intact (Figure 1D). Treated with sitagliptin of MIC, P. gingivalis cell membrane was shrunken (Figure 1E). And treated with sitagliptin of $\mathrm{MBC}$, perforation of cell membrane was observed and the cell structures were totally ruptured (Figure 1F). Thus, cell membrane may be a sensitive target for sitagliptin against $P$. gingivalis.

\section{Effect of sitagliptin at sub-MIC on P. gingivalis}

\subsection{P. gingivalis growth assay}

Following 48-hour incubation, the $\mathrm{OD}_{600}$ value of $\mathrm{P}$. gingivalis suspension without or with sitagliptin of sub-MIC was measured. No statistically significant difference was found between the turbidity of the P. gingivalis suspension without or with sitagliptin (up to $50 \mu \mathrm{g} / \mathrm{ml}, 1 / 5 \mathrm{MIC}$ ), demonstrating the lack of effect of sitagliptin (1/5 MIC) on bacterial growth (Figure 2). 


\subsection{Early adhesion to titanium and bacterial aggregation}

The early adhesion of P. gingivalis to SLA discs was visually observed by SEM. In the control group, more P. gingivalis cells observed adhered to the SLA discs and clumped together (Figure 3A), while fewer cells adhered to the discs and distributed separately after incubating with sitagliptin (Figure 3B).

To quantificationally measure the P. gingivalis early adhered to the SLA discs, CCK8 method were used. As shown in Figure 3C, sitagliptin of $50 \mu \mathrm{g} / \mathrm{ml}$ significantly reduced $P$. gingivalis early adhesion to the SLA discs. And to determine the $P$. gingivalis bacterial aggregation, the $\mathrm{OD}_{600 \mathrm{~nm}}$ value of the bacterial suspension was recorded. As shown in Figure 3D, the aggregation rate was 57.33\% $\pm 4.04 \%$ after incubation while the rate decrease to $47.67 \% \pm 4.73 \%$ after incubating with sitagliptin.

\subsection{Bacterial hemagglutination and hemolysis}

As shown in Figure 4A, bacterial hemagglutination was detected visibly up to the bacteria dilution of 1:8 after incubating without sitagliptin or with sitagliptin of 25 $\mu \mathrm{g} / \mathrm{ml}$, whereas hemagglutination was observed up to the bacteria dilution of $1: 4$ with $50 \mu \mathrm{g} / \mathrm{ml}$ of sitagliptin indicating the effect of sitagliptin at $50 \mu \mathrm{g} / \mathrm{ml}$ on hemagglutination activity.

And bacterial hemolysis, as shown in Figure 4B, decreased significantly from $46.23 \%$ $\pm 2.05 \%$ without sitagliptin to $31.07 \% \pm 3.02 \%$ with $50 \mu \mathrm{g} / \mathrm{ml}$ of sitagliptin which demonstrated that effect of sitagliptin at sub-MIC on bacterial hemolytic activities.

\subsection{Expressions of virulence factors}

As shown in Figure 5, compared with P. gingivalis incubated without sitagliptin, sitagliptin at $50 \mu \mathrm{g} / \mathrm{ml}$ significantly decreased the gene expressions of all tested virulence factors including hemolysin (hem), fimbriae (fimA), arginine-specific gingipains (rgpA), lysine-specific gingipain (kgp) and ferritin (ftn).

\section{Effect of sitagliptin on inflammatory response in RAW 264.7}

\subsection{Cytotoxicity assay}

To determine the cytotoxicity of sitagliptin at different doses, the CCK-8 assay was performed after RAW264.7 cells incubated without or with sitagliptin (10, 25, 50, 75 and $100 \mu \mathrm{g} / \mathrm{ml}$ ) for $24 \mathrm{~h}$. As shown in Figure 6A, sitagliptin had no effect on cells viability at concentrations of up to $50 \mu \mathrm{g} / \mathrm{ml}$.

And to the cytotoxicity of sitagliptin with Pg-LPS stimulation, viability of cells treated with sitagliptin in the absence or presence of $5 \mu \mathrm{g} / \mathrm{ml}$ of Pg-LPS for $24 \mathrm{~h}$ was detected. The CCK-8 assay demonstrated that no significant difference of cell viability between the control group (without sitagliptin and LPS) and the treated 
group was found (Figure 6B).

\subsection{Protective effect of sitagliptin against the polarization of M1 cells}

RAW264.7 cells were treated with or without $50 \mu \mathrm{g} / \mathrm{ml}$ of sitagliptin in the absence or presence of $5 \mu \mathrm{g} / \mathrm{ml}$ of Pg-LPS. The ratio of CD86/CD206 of the control group was $0.75 \pm 0.03$, while that of the treatment with $5 \mu \mathrm{g} / \mathrm{ml}$ of Pg-LPS was increased to 2.05 \pm 0.05 showing that Pg-LPS promoted the polarization of M1 cells (Figure 7 A,B,D). Compared to the treatment with Pg-LPS, treatment with Pg-LPS and $50 \mu \mathrm{g} / \mathrm{ml}$ of sitagliptin decreased the ratio to $1.59 \pm 0.12$ indicating the protective effect of sitagliptin against the polarization of M1 cells (Figure 7 C,D).

\subsection{Attenuating effect of sitagliptin on the expression of inflammation-related cytokine in response to $P$. gingivalis LPS}

To determine the effect of sitagliptin on proinflammatory cytokine expression, ELISA and RT-PCR assay were performed. At transcriptional level, the expression of proinflammatory cytokine including IL-1 $\beta$, IL-6, TNF- $\alpha$, iNOS, IL12-P35 and IL12-P40 was significantly increased by $5 \mu \mathrm{g} / \mathrm{ml}$ of Pg-LPS, while it decreased significantly after treatment with $50 \mu \mathrm{g} / \mathrm{ml}$ of sitagliptin (Figure $8 \mathrm{~A}$ ). At translational level, treatment with sitagliptin and LPS also significantly downregulated the enhancement of IL-1 $\beta$ and IL-6 stimulated by LPS (Figure 8 B,C).

\subsection{Inhibiting effect of sitagliptin on activation of MAPK and AKT signaling pathways}

To investigate the underlying mechanism of anti-inflammatory effect of sitagliptin, the effect of sitagliptin on the MAPK and AKT signaling pathways was examined. As shown in figure 9, $5 \mu \mathrm{g} / \mathrm{ml}$ of Pg-LPS stimulation significantly increased the phosphorylation of p38 MAPK, AKT and ERK. However, treatment with $50 \mu \mathrm{g} / \mathrm{ml}$ of sitagliptin significantly inhibited phosphorylation of p38, AKT and ERK indicating that sitagliptin suppressed the MAPK and AKT signaling pathways.

\section{Discussion}

Peri-implantitis is a plaque-induced inflammatory disease that may lead to dental failure [6]. For the treatment of peri-implantitis, drug therapy, mostly with antibiotics, is an essential adjunctive method [33]. However, considering the possible drug resistance and side effects of antibiotics, more and more studies have focused on the potential alternatives. Current evidence pointed out that diabetes was an important risk factor of peri-implantitis [34-36], thus in this present study, we carried out the in vitro experiment to explore the possible application of sitagliptin, a traditional glucose-lowering agent for type 2 diabetes patients, in attenuating the P.gingivalis virulence and subsequent inflammatory response in peri-implantitis.

P.gingivalis is a key periodontal pathogen and strongly associated with peri-implantitis [37]. In the present study, we determined that sitagliptin not only inhibited the growth of planktonic P. gingivalis but also impaired P. gingivalis biofilm 
by inhibiting biofilm formation, eliminating established biofilm, and reducing biofilm viability, which may be on the ground of the inhibiting effect of sitagliptin on $\mathrm{X}$-prolyl dipeptidyl aminopeptidase that is similar to DPP-4 and plays a role in virulence of P.gingivalis [23]. And by SEM, we observed the perforation of $\mathrm{P}$. gingivalis cell membrane treated with sitagliptin of $\mathrm{MBC}$, hence we speculated that the cell membrane may be a sensitive target for sitagliptin against $\mathrm{P}$. gingivalis.

Besides, we studied the effect of sitagliptin at sub-MIC on the phenotypic behavior of P. gingivalis. For non-motile bacteria like P. gingivalis, adhesion is the initial step for the bioflm formation [38]. The $50 \mu \mathrm{g} / \mathrm{ml}(1 / 5 \mathrm{MIC})$ of sitagliptin significantly reduced early adhesion of $\mathrm{P}$. gingivalis compared to the control. This may be due to the anti-QS activity of triazole derivatives including sitagliptin, which controls diverse physiological functions of bacteria such as adhesion, hemolysis, production of biofilm and swimming . Aggregation is a process through which a strain within the biofilm produces polymers to integrate genetically identical strains and is also a significant prerequisite of biofilm formation [40, 41]. Treated with sitagliptin, the P. gingivalis observed by SEM distributed more separately and the aggregation rate detected by microplate assay decreased significantly determining the effect of sitagliptin on P. gingivalis aggregation.

In the present study, we also investigated the effect of sitagliptin on hemagglutination and hemolysis of P. gingivalis. Different to other bacteria, P. gingivalis cannot take in iron and biosynthesize heme for the lack of a siderophore scavenging system and the required enzymes, while it obtains heme directly from erythrocytes adopting alternative mechanisms [42]. The mechanisms involve the hemagglutinating and hemolytic activities of P.ingivalis, which is a feature distinguishing this organism from other black-pigmented anaerobes [43]. Our results determined the inhibiting effect of sitagliptin at $50 \mu \mathrm{g} / \mathrm{ml}$ on the hemagglutination and hemolysis of P.gingivalis, indicating that sitagliptin may play a significant role in attenuating virulence of $P$. gingivalis by controlling the heme acquisition of $\mathrm{P}$. gingivalis.

To detect the effect of sitagliptin on the gene expressions related to $\mathrm{P}$. gingivalis virulence, our study performed real-time PCR analysis. Our results demonstrated that sitagliptin at $50 \mu \mathrm{g} / \mathrm{ml}$ significantly decreased the gene expressions of all tested virulence factors including arginine-specific gingipains (rgpA), lysine-specific gingipain (kgp), fimbriae (fimA), hemolysin (hem) and ferritin (ftn). Among them, rgpA and kgp genes are involved with gingipain, which has been extensively studied and are considered to be responsible for bacterial adhesion, hemagglutination and hemolytic activities, host tissue destruction by inducing matrix metalloproteinase production and stimulation inflammatory response [44-46]. FimA gene is responsible for adhesion, co-aggression and interaction with TLR-2 receptor mediating pro-inflammatory cytokines production $[38,47]$. Hem is related to hemolysis activity facilitating the acquisition of heme from erythrocytes, which is necessary for bacterial growth [30]. And ftn gene involves with intracellular $\mathrm{Fe}^{2+}$ storage and particularly significant for $\mathrm{P}$. gingivalis to survive under iron deprived conditions [48, 49]. Therefore, the PCR results further determined that sitagliptin inhibited the above P. gingivalis virulence at the transcriptional level. 
In the inflammatory progress of peri-implantitis, the polarization of macrophage plays a considerable role $[10,12]$. It is reported that macrophages reveal a higher expression for M1 phenotype and accordingly a higher M1/M2 ratio at peri-implantitis sites [12]. Thus in the present study, we detected the effect of sitagliptin on polarization of RAW264.7 via flow cytometry assay. On account of that CD86 is the characteristic marker of M1 macrophages while CD206 is primarily expressed by M2 macrophages [50], CD86 and CD206 were selected as M1 and M2 markers for flow analysis. It is generally accepted that macrophages activated by bacteria sub-products LPS present a M1 phenotype [10], which is consistent with our result that RAW264.7 cells presented a higher expression of M1 treated with Pg-LPS. However, RAW264.7 treated with Pg-LPS and sitagliptin presented a lower expression of M1 and a lower M1/M2 ratio showing the protective effect of sitagliptin on the macrophage polarization.

Macrophages presenting a M1 phenotype are associated with pro-inflammatory responses, tissue destruction, and pro-inflammatory cytokine production [10]. Thus we further detected the effect of sitagliptin on the inflammation-related cytokine expression of RAW264.7 stimulated by Pg-LPS and found that sitagliptin significantly downregulated the enhancement of IL-1 $\beta$, TNF- $\alpha$, IL- 6 stimulated by LPS at transcriptional level and IL-1 $\beta$ and IL-6 at translational level. It is demonstrated that peri-implantitis sites were associated with a significant increase in levels of IL-1 $\beta$ and TNF- $\alpha$ compared to healthy implants [51]. IL-1 $\beta$ is mainly produced in macrophages and regulates the degradation of collagenase activity and extracellular matrix components of the plasminogen system in inflammation [52]. And TNF- $\alpha$ induces fibroblast apoptosis and reduction of the repair capacity of the peri-implant tissue [53]. Besides, IL-6, another one of the most investigated pro-inflammatory cytokines between healthy and diseased peri-implant tissues, is conspicuous in chronic peri-implant inflammation, leading to osteoclastic activation and peri-implant bone loss [54]. We also found that sitagliptin decreased the mRNA expression of iNOS, IL-12 p35 and IL-12 p40. INOs is the M1 macrophage marker gene and its activation results in further propagation of inflammatory responses [55]. And IL-12, composed of p35 and p40 subunits, is processed by macrophages correlating with bacterial clearance [56]. IL-12 is not toxic itself but prompts a neutrophil response that determined the severity of tissue damage $[57,58]$, therefore our results may suggest that sitagliptin can control excessive levels of IL-12.

Studies determined the important roles of MAPK and AKT signaling pathways in peri-implantitis [59-61]. Our study showed that P. gingivalis LPS significantly enhanced the phosphorylation of p38 MAPK, AKT and ERK while the treatment of sitagliptin decreased the phosphorylation, suggesting that sitagliptin may exert anti-inflammatory effects by inhibiting the MAPK and AKT signaling pathways.

Taken together, our study demonstrated the attenuating effect of sitagliptin on the growth, phenotypic behavior and virulence factors of $\mathrm{P}$. gingivalis and the protective effect on the P. gingivalis LPS-induced polarization in macrophage. And we also confirmed the anti-inflammatory effect of sitagliptin on the secretion of inflammation-related factors in macrophage stimulated by P. gingivalis LPS by inhibiting the MAPK and AKT signaling pathways. And it is the first in vitro study on 
the inhibiting effect of sitagliptin on P.gingivalis virulence and inflammatory response in P.gingivalis LPS-stimulated macrophage on titanium suggesting the potential therapeutic role of the anti-diabetic drug sitagliptin in peri-implantitis, particularly in patients with type 2 diabetes. However, the above effects of sitagliptin surrounding implant in vivo or in a high-glucose environment, need to be further studied.

\section{Competing interests}

The authors declare that they have no competing interests.

\section{Funding}

This research did not receive any specific grant from funding agencies in the public, commercial, or not-for-profit sectors.

\section{Conflict of Interest Statement}

The authors declare that the research was conducted in the absence of any commercial or financial relationships that could be construed as a potential conflict of interest.

\section{Author Contributions}

W.T., M.D., S.Z., H.J.: conception and design; W.T., S.Z.: experiments and/or data analysis; M.D.: clinical consultancy; H.J.: intellectual input and supervision; W.T.: writing-original draft; S.Z.:writing-review and editing. 


\section{Declarations}

\section{Ethics approval and consent to participate}

Not applicable.

\section{Consent for publication}

Not applicable.

\section{Availability of data and materials}

The datasets supporting the conclusions of this article are included within the article. Additional data will be available upon request from corresponding author.

\section{Acknowledgements}

Not applicable.

\section{Author information}

Shuang Zhang and Han Jiang share the correspondence authors and both contributed equally to this study. 


\section{Table}

Table1. Primer sequences used for transcription analysis of $\mathrm{P}$. gingivalis virulence-associated genes.

\begin{tabular}{|c|c|c|}
\hline \multirow[t]{2}{*}{ Gene } & \multicolumn{2}{|c|}{ Primer sequence $\left(5^{\prime}-3^{\prime}\right)$} \\
\hline & Forward & Reverse \\
\hline 16S rRNA & CGGGAATAACGGGCGATACG & TACCGAACAACCTACGCACC \\
\hline Kgp & ATGTTGCCTTCCGCCACTTCG & CTCCGTTACGCCTGATGCTATCTG \\
\hline FimA & TTGTTGGGACTTGCTGCTCTTG & TTCGGCTGATTTGATGGCTTCC \\
\hline Hem & ACGAAGCCTTGTTCTCCTCA & CAATGAATATGCCGGTTTCC \\
\hline RgpA & CCGAGCACGAAAACCAA & GGGGCATCGCTGACTG \\
\hline Ftn & GCGTGGCGGCGAGGTGAAG & CGGAAGCAGCCCTTACGACAGC \\
\hline
\end{tabular}


Table2. Primer sequences used for transcription analysis of RAW264.7 inflammation-related cytokine genes.

\begin{tabular}{ccc}
\hline \multirow{2}{*}{ Gene } & \multicolumn{2}{c}{ Primer sequence $\left(5^{\prime}-3^{\prime}\right)$} \\
\cline { 2 - 3 } Forward & \multicolumn{1}{c}{ Reverse } \\
IL-1 3 & AGGAGAACCAAGCAACGACA & CTTGGGATCCACACTCTCCAG \\
IL-6 & ACAAGTCCGGAGAGGAGACT & AATTGCCATTGCACAACTCTT \\
iNOS & GGAGCATCCCAAGTACGAGT & CCAATCTCGGTGCCCATGTA \\
IL-10 & CAGTACAGCCGGGAAGACAA & TGGCAACCCAAGTAACCCTTA \\
IL-12 p40 & ACAGCACCAGCTTCTTCATCAG & TCTTCAAAGGCTTCATCTGCAA \\
IL-12 p35 & CCAAGGTCAGCGTTCCAACA & AGAGGAGGTAGCGTGATTGACA \\
\hline
\end{tabular}

Table3. The antimicrobial assay of sitagliptin against $\mathrm{P}$. gingivalis

\begin{tabular}{lccccccc}
\hline \multirow{2}{*}{ Drug } & \multicolumn{2}{c}{ Planktonic P. gingivalis } & & \multicolumn{3}{c}{ Biofilm of P. gingivalis } \\
\cline { 2 - 3 } \cline { 5 - 7 }$(\mu \mathrm{g} / \mathrm{ml})$ & MIC & MBC & & MBIC $_{50}$ & MBRC $_{50}$ & SMIC $_{50}$ \\
\hline Sitagliptin & 250 & 2500 & & 500 & 2000 & 1000 \\
\hline
\end{tabular}




\section{Figure Legend}

Figure1. Antibiofilm activity of sitagliptin and morphological changes of P. gingivalis. (A)After $48 \mathrm{~h}$ of incubation with different concentrations of sitagliptin, a crystal violet staining assay was conducted and the $\mathrm{OD}_{560}$ value were recorded. (B) Mature biofilm was treated with sitagliptin for $24 \mathrm{~h}$ followed by a crystal violet staining assay and recordation of $\mathrm{OD}_{560}$ value. (C) Mature biofilm was incubated with sitagliptin for $24 \mathrm{~h}$ followed by a CCK8 assay and recordation of $\mathrm{OD}_{450}$ value. Data from three independent experiments were shown as mean \pm standard deviation (SD). (*P $<0.05,{ }^{*} \mathrm{P}<0.01,{ }^{* * *} \mathrm{P}<0.001,{ }^{* * * *} \mathrm{P}<0.0001$ compared with $\mathrm{P}$. gingivalis incubated without sitagliptin). (D-F) Morphological changes of P. gingivalis were observed by SEM. (D) Cells observed in the control group were plump and cell membranes remained clearly intact. (E) Treated with sitagliptin of MIC, cell membrane was shrunken (red arrows). (F) Treated with sitagliptin of $\mathrm{MBC}$, perforation of cell membrane (red arrows) was observed and the cell structures were totally ruptured .

Figure2. Effect of sitagliptin at sub-MIC on P. gingivalis growth. Following 48-hour incubation, the $\mathrm{OD}_{600}$ value of $\mathrm{P}$. gingivalis suspension without or with sitagliptin of sub-MIC was measured. Data were expressed as mean $\pm \mathrm{SD} . * * \mathrm{P}<0.01,{ }^{* * *} \mathrm{P}<0.001$ compared with $\mathrm{P}$. gingivalis incubated without sitagliptin.

Figure3. Effect of sitagliptin at sub-MIC on P. gingivalis early adhesion and aggregation. (A,B) The SLA discs were immersed in P. gingivalis suspension with 0,25 and $50 \mu \mathrm{g} / \mathrm{ml}$ of sitagliptin and then incubated for $4 \mathrm{~h}$ anaerobically.The early adhered P. gingivalis (red arrows) to SLA discs was visually observed by SEM. (A)In the untreated group, more P. gingivalis cells observed adhered to the SLA discs and clumped together, (B)while fewer cells adhered to the discs and distributed separately in the treatment with sitagliptin of $50 \mu \mathrm{g} / \mathrm{ml}$. (C)A CCK8 assay was performed and data were shown as mean \pm SD. (D)P. gingivalis were incubated with sitagliptin of sub-MIC overnight anaerobically. Harvested by centrifugation, the bacteria were rinsed and re-suspended.The $\mathrm{OD}_{600 \mathrm{~nm}}$ value of the suspension was recorded after $3 \mathrm{~h}$. The percentage of aggregation was calculated by the following equation: Aggregation rate $=\left(\mathrm{OD}_{\text {Initial }}-\mathrm{OD}_{3 \mathrm{~h}}\right) /$ $\mathrm{OD}_{\text {Initial }} \times 100 \%$. $* \mathrm{P}<0.05,{ }^{* *} \mathrm{P}<0.01$ compared with $\mathrm{P}$. gingivalis incubated without sitagliptin.

Figure 4. Effect of sitagliptin at sub-MIC on bacterial hemagglutination and hemolysis.(A) Overnight cultures of $\mathrm{P}$. gingivalis with sitagliptin were harvested, centrifuged, and re-suspended. The bacteria suspension were serially diluted and mixed with sitagliptin of sub-MIC and erythrocytes suspension. After incubation for 3h, hemagglutination was detected visibly. (B) After washing and diluting, sheep erythrocytes were added in bacteria suspension with or without sitagliptin. The $\mathrm{OD}_{540}$ value was recorded. ${ }^{* *} \mathrm{P}<0.001$ compared with $\mathrm{P}$. gingivalis incubated without sitagliptin.

Figure 5. Effect of sitagliptin at sub-MIC on the expressions of virulence factors. The sitagliptin of sub-MIC was added to bacterial cultures $\left(\mathrm{OD}_{600}=0.8\right)$ prior to anaerobic culturing at $37^{\circ} \mathrm{C}$ for $24 \mathrm{~h}$. Transcriptional levels of the virulence genes of $\mathrm{P}$. gingivalis were detected by real time-PCR. $* \mathrm{P}<0.05,{ }^{*} \mathrm{P}<0.01,{ }^{* * *} \mathrm{P}<0.001,{ }^{* * * *} \mathrm{P}<0.0001$ compared with $\mathrm{P}$. gingivalis incubated 
without sitagliptin.

Figure 6. Cytotoxicity assay.(A) Viability of cells treated with different concentrations of sitagliptin and (B) with sitagliptin in the absence or presence of Pg-LPS of $5 \mu \mathrm{g} / \mathrm{ml}$ for $24 \mathrm{~h}$ was detected by CCK $8 .{ }^{* *} \mathrm{P}<0.01,{ }^{* * * *} \mathrm{P}<0.0001$ compared with untreated group.

Figure 7. Protective effect of sitagliptin on macrophages polarization. (A) Flow cytometry assay of macrophages polarization of the untreated group; (B) flow cytometry assay of macrophages polarization of the treatment with $5 \mu \mathrm{g} / \mathrm{ml}$ of Pg-LPS ; (C) flow cytometry assay of macrophages polarization of the treatment with $5 \mu \mathrm{g} / \mathrm{ml}$ of Pg-LPS and $50 \mu \mathrm{g} / \mathrm{ml}$ of sitagliptin; (D) analysis of the ratio of $\mathrm{M} 1 / \mathrm{M} 2$. Data were expressed as mean $\pm \mathrm{SD}$. $* \mathrm{P}<0.05$ and $* * * \mathrm{P}<0.001$ compared with cells treated with Pg-LPS.

Figure 8. Sitagliptin attenuates the expression of inflammation-related cytokine in response to $\mathrm{P}$. gingivalis LPS. (A) Relative levels of IL-1 $\beta$, IL-6, TNF- $\alpha$, iNOS, IL12-P35 and IL12-P40 mRNA determined by qPCR. (B) Proteins levels of IL-1 $\beta$ and (C) IL-6 in supernatants measured by ELISA. (B,C) Data were expressed as mean \pm SD. ${ }^{*} \mathrm{P}<0.05$, ${ }^{*} \mathrm{P}<0.01$ and $* * * \mathrm{P}<0.001$ compared with cells treated with Pg-LPS.

Figure 9. Sitagliptin Inhibits Activation of MAPK and AKT Signaling Pathways. RAW264.7 cells were treated with or without $50 \mu \mathrm{g} / \mathrm{ml}$ of sitagliptin in the absence or presence of $5 \mu \mathrm{g} / \mathrm{ml}$ of Pg-LPS. (A) Cell lysates were subjected to Western blot analysis. (B) The band intensities were quantified by Image J analysis. Data were expressed as mean $\pm \mathrm{SD} . \quad * \mathrm{p}<0.05$ compared with treatment with Pg-LPS. ** $\mathrm{p}<0.05$ compared with Group1. 


\section{References:}

1. Brånemark PI, Adell R, Breine U, Hansson BO, Lindström J, Ohlsson A: Intra-osseous anchorage of dental prostheses. I. Experimental studies. Scand J Plast Reconstr Surg 1969, 3(2):81-100.

2. Brånemark PI: Osseointegration and its experimental background. J PROSTHET DENT 1983, 50(3):399-410.

3. Jemt T: Implant Survival in the Edentulous Jaw: 30 Years of Experience. Part II: A Retro-Prospective Multivariate Regression Analysis Related to Treated Arch and Implant Surface Roughness. INT J PROSTHODONT 2018, 31(6):531-539.

4. Jemt T: Implant Survival in the Edentulous Jaw-30 Years of Experience. Part I: A Retro-Prospective Multivariate Regression Analysis of Overall Implant Failure in 4,585 Consecutively Treated Arches. INT J PROSTHODONT 2018, 31(5):425-435.

5. Alhilou A, Do T, Mizban L, Clarkson BH, Wood DJ, Katsikogianni MG: Physicochemical and Antibacterial Characterization of a Novel Fluorapatite Coating. ACS Omega 2016, 1(2):264-276.

6. Schwarz F, Derks J, Monje A, Wang HL: Peri-implantitis. J CLIN PERIODONTOL 2018, 45 Suppl 20:S246-S266.

7. Camargo S, Roy T, Carey IP, Fares C, Ren F, Clark AE, Esquivel-Upshaw JF: Novel Coatings to Minimize Bacterial Adhesion and Promote Osteoblast Activity for Titanium Implants. J Funct Biomater 2020, 11(2).

8. Di Giulio M, Traini T, Sinjari B, Nostro A, Caputi S, Cellini L: Porphyromonas gingivalis biofilm formation in different titanium surfaces, an in vitro study. CLIN ORAL IMPLAN RES 2016, 27(7):918-925.

9. Berglundh T, Gislason O, Lekholm U, Sennerby L, Lindhe J: Histopathological observations of human periimplantitis lesions. J CLIN PERIODONTOL 2004, 31(5):341-347.

10. Garlet GP, Giannobile WV: Macrophages: The Bridge between Inflammation Resolution and Tissue Repair? J DENT RES 2018, 97(10):1079-1081.

11. Louiselle AE, Niemiec SM, Zgheib C, Liechty KW: Macrophage polarization and diabetic wound healing. TRANSL RES 2021.

12. Galarraga-Vinueza ME, Obreja K, Ramanauskaite A, Magini R, Begic A, Sader R, Schwarz F: Macrophage polarization in peri-implantitis lesions. Clin Oral Investig 2021, 25(4):2335-2344.

13. Garaicoa-Pazmino C, Fretwurst T, Squarize CH, Berglundh T, Giannobile WV, Larsson L, Castilho RM: Characterization of macrophage polarization in periodontal disease. $J$ CLIN PERIODONTOL 2019, 46(8):830-839.

14. Hemmingsen B, Sonne DP, Metzendorf MI, Richter B: Dipeptidyl-peptidase (DPP)-4 inhibitors and glucagon-like peptide (GLP)-1 analogues for prevention or delay of type 2 diabetes mellitus and its associated complications in people at increased risk for the development of type 2 diabetes mellitus. Cochrane Database Syst Rev 2017, 5(5):D12204.

15. Wang M, Zhang X, Ni T, Wang Y, Wang X, Wu Y, Zhu Z, Li Q: Comparison of New Oral Hypoglycemic Agents on Risk of Urinary Tract and Genital Infections in Type 2 Diabetes: A Network Meta-analysis. ADV THER 2021, 38(6):2840-2853.

16. Zheng Z, Liang P, Hou B, Lu X, Ma Q, Yu X, Han S, Peng B, Chen T, Liu W et al: The effect of dipeptidyl peptidase IV on disease-associated microglia phenotypic transformation in epilepsy. J Neuroinflammation 2021, 18(1):112. 
17. Mozafari N, Azadi S, Mehdi-Alamdarlou S, Ashrafi H, Azadi A: Inflammation: A bridge between diabetes and COVID-19, and possible management with sitagliptin. $M E D$ HYPOTHESES 2020, 143:110111.

18. Wang C, Xiao F, Qu X, Zhai Z, Hu G, Chen X, Zhang X: Sitagliptin, An Anti-diabetic Drug, Suppresses Estrogen Deficiency-Induced OsteoporosisIn Vivo and Inhibits RANKL-Induced Osteoclast Formation and Bone Resorption In Vitro. FRONT PHARMACOL 2017, 8:407.

19. Yazbeck R, Jaenisch SE, Abbott CA: Dipeptidyl peptidase 4 inhibitors: Applications in innate immunity? BIOCHEM PHARMACOL 2021, 188:114517.

20. Nemoto TK, Ohara NY: Dipeptidyl-peptidases: Key enzymes producing entry forms of extracellular proteins in asaccharolytic periodontopathic bacterium Porphyromonas gingivalis. MOL ORAL MICROBIOL 2021, 36(2):145-156.

21. Banbula A, Bugno M, Goldstein J, Yen J, Nelson D, Travis J, Potempa J: Emerging family of proline-specific peptidases of Porphyromonas gingivalis: purification and characterization of serine dipeptidyl peptidase, a structural and functional homologue of mammalian prolyl dipeptidyl peptidase IV. INFECT IMMUN 2000, 68(3):1176-1182.

22. Ohara-Nemoto Y, Rouf SM, Naito M, Yanase A, Tetsuo F, Ono T, Kobayakawa T, Shimoyama Y, Kimura S, Nakayama $\mathrm{K}$ et al: Identification and characterization of prokaryotic dipeptidyl-peptidase 5 from Porphyromonas gingivalis. J BIOL CHEM 2014, 289(9):5436-5448.

23. De A, Pompilio A, Francis J, Sutcliffe IC, Black GW, Lupidi G, Petrelli D, Vitali LA: Antidiabetic "gliptins" affect biofilm formation by Streptococcus mutans. MICROBIOL RES 2018, 209:79-85.

24. Abbas HA, Hegazy W: Repurposing anti-diabetic drug "Sitagliptin" as a novel virulence attenuating agent in Serratia marcescens. PLOS ONE 2020, 15(4):e231625.

25. Abbas HA, Shaldam MA, Eldamasi D: Curtailing Quorum Sensing in Pseudomonas aeruginosa by Sitagliptin. CURR MICROBIOL 2020, 77(6):1051-1060.

26. Zhang S, Wang M, Jiang $\mathrm{T}$, Zhou $\mathrm{Y}$, Wang $\mathrm{Y}$ : Roles of a new drug-delivery healing abutment in the prevention and treatment of peri-implant infections: a preliminary study. $R S C A D V 2018$, 8(68):38836-38843.

27. Zhou W, Zhang X, Zhu CL, He ZY, Liang JP, Song ZC: Melatonin Receptor Agonists as the "Perioceutics" Agents for Periodontal Disease through Modulation of Porphyromonas gingivalis Virulence and Inflammatory Response. PLOS ONE 2016, 11(11):e166442.

28. Zhong H, Xie Z, Wei H, Zhang S, Song Y, Wang M, Zhang Y: Antibacterial and Antibiofilm Activity of Temporin-GHc and Temporin-GHd Against Cariogenic Bacteria, Streptococcus mutans. FRONT MICROBIOL 2019, 10:2854.

29. Li X, Yu C, Hu Y, Xia X, Liao Y, Zhang J, Chen H, Lu W, Zhou W, Song Z: New Application of Psoralen and Angelicin on Periodontitis With Anti-bacterial, Anti-inflammatory, and Osteogenesis Effects. Front Cell Infect Microbiol 2018, 8:178.

30. He Z, Zhang X, Song Z, Li L, Chang H, Li S, Zhou W: Quercetin inhibits virulence properties of Porphyromas gingivalis in periodontal disease. Sci Rep 2020, 10(1):18313.

31. Eltigani SA, Eltayeb MM, Ishihara A, Arima J: Isolates from Monechma ciliatum seeds' extract hampered Porphyromonas gingivalis hemagglutinins. J FOOD BIOCHEM 2019, 43(11):e13029.

32. Abdolhosseini M, Nandula SR, Song J, Hirt H, Gorr SU: Lysine substitutions convert a bacterial-agglutinating peptide into a bactericidal peptide that retains anti-lipopolysaccharide activity and low hemolytic activity. PEPTIDES 2012, 35(2):231-238. 
33. Kormas I, Pedercini C, Pedercini A, Raptopoulos M, Alassy H, Wolff LF: Peri-Implant Diseases: Diagnosis, Clinical, Histological, Microbiological Characteristics and Treatment Strategies. A Narrative Review. Antibiotics (Basel) 2020, 9(11).

34. Alrabiah M, Al-Aali KA, Al-Sowygh ZH, Binmahfooz AM, Mokeem SA, Abduljabbar T: Association of advanced glycation end products with peri-implant inflammation in prediabetes and type 2 diabetes mellitus patients. Clin Implant Dent Relat Res 2018, 20(4):535-540.

35. Shang R, Gao L: Impact of hyperglycemia on the rate of implant failure and peri-implant parameters in patients with type 2 diabetes mellitus: Systematic review and meta-analysis. $J$ AM DENT ASSOC 2021, 152(3):189-201.

36. Jiang $\mathrm{X}$, Zhu Y, Liu Z, Tian Z, Zhu S: Association between diabetes and dental implant complications: a systematic review and meta-analysis. ACTA ODONTOL SCAND 2021, 79(1):9-18.

37. Shibli JA, Melo L, Ferrari DS, Figueiredo LC, Faveri M, Feres M: Composition of supra- and subgingival biofilm of subjects with healthy and diseased implants. Clin Oral Implants Res 2008, 19(10):975-982.

38. Kumbar VM, Peram MR, Kugaji MS, Shah T, Patil SP, Muddapur UM, Bhat KG: Effect of curcumin on growth, biofilm formation and virulence factor gene expression of Porphyromonas gingivalis. ODONTOLOGY 2021, 109(1):18-28.

39. Wright CJ, Burns LH, Jack AA, Back CR, Dutton LC, Nobbs AH, Lamont RJ, Jenkinson HF: Microbial interactions in building of communities. MOL ORAL MICROBIOL 2013, 28(2):83-101.

40. He Z, Huang Z, Zhou W, Tang Z, Ma R, Liang J: Anti-biofilm Activities from Resveratrol against Fusobacterium nucleatum. FRONT MICROBIOL 2016, 7:1065.

41. Abdel-Nour M, Duncan C, Prashar A, Rao C, Ginevra C, Jarraud S, Low DE, Ensminger AW, Terebiznik MR, Guyard C: The Legionella pneumophila collagen-like protein mediates sedimentation, autoaggregation, and pathogen-phagocyte interactions. Appl Environ Microbiol 2014, 80(4):1441-1454.

42. Eltigani SA, Eltayeb MM, Ishihara A, Arima J: Isolates from Monechma ciliatum seeds' extract hampered Porphyromonas gingivalis hemagglutinins. J FOOD BIOCHEM 2019, 43(11):e13029.

43. Olczak T, Simpson W, Liu X, Genco CA: Iron and heme utilization in Porphyromonas gingivalis. FEMS MICROBIOL REV 2005, 29(1):119-144.

44. Zhang R, Yang J, Wu J, Sun WB, Liu Y: Effect of deletion of the rgpA gene on selected virulence of Porphyromonas gingivalis. J DENT SCI 2016, 11(3):279-286.

45. Tantivitayakul P, Kaypetch R, Muadchiengka T: Thymoquinone inhibits biofilm formation and virulence properties of periodontal bacteria. ARCH ORAL BIOL 2020, 115:104744.

46. Imamura $\mathrm{T}$ : The role of gingipains in the pathogenesis of periodontal disease. $J$ PERIODONTOL 2003, 74(1):111-118.

47. Hajishengallis G, Tapping RI, Harokopakis E, Nishiyama S, Ratti P, Schifferle RE, Lyle EA, Triantafilou M, Triantafilou K, Yoshimura F: Differential interactions of fimbriae and lipopolysaccharide from Porphyromonas gingivalis with the Toll-like receptor 2-centred pattern recognition apparatus. CELL MICROBIOL 2006, 8(10):1557-1570.

48. James CE, Hasegawa Y, Park Y, Yeung V, Tribble GD, Kuboniwa M, Demuth DR, Lamont RJ: LuxS involvement in the regulation of genes coding for hemin and iron acquisition systems in Porphyromonas gingivalis. INFECT IMMUN 2006, 74(7):3834-3844.

49. Ratnayake DB, Wai SN, Shi Y, Amako K, Nakayama H, Nakayama K: Ferritin from the obligate 
anaerobe Porphyromonas gingivalis: purification, gene cloning and mutant studies. Microbiology (Reading) 2000, 146 ( Pt 5):1119-1127.

50. Hou Y, Yu H, Liu X, Li G, Pan J, Zheng C, Yu W: Gingipain of Porphyromonas gingivalis manipulates M1 macrophage polarization through C5a pathway. In Vitro Cell Dev Biol Anim 2017, 53(7):593-603.

51. Alassy H, Parachuru P, Wolff L: Peri-Implantitis Diagnosis and Prognosis Using Biomarkers in Peri-Implant Crevicular Fluid: A Narrative Review. Diagnostics (Basel) 2019, 9(4).

52. Delima AJ, Van Dyke TE: Origin and function of the cellular components in gingival crevice fluid. PERIODONTOL 2000 2003, 31:55-76.

53. Faot F, Nascimento GG, Bielemann AM, Campão TD, Leite FR, Quirynen M: Can peri-implant crevicular fluid assist in the diagnosis of peri-implantitis? A systematic review and meta-analysis. J PERIODONTOL 2015, 86(5):631-645.

54. Ghassib I, Chen Z, Zhu J, Wang HL: Use of IL-1 $\beta$, IL-6, TNF- $\alpha$, and MMP-8 biomarkers to distinguish peri-implant diseases: A systematic review and meta-analysis. Clin Implant Dent Relat Res 2019, 21(1):190-207.

55. Kamalian A, Sohrabi AM, Dolatshahi M, Afshari K, Shamshiri S, Momeni RN, Momtaz S, Rahimi R, Abdollahi $\mathrm{M}$, Abdolghaffari $\mathrm{AH}$ : Interventions of natural and synthetic agents in inflammatory bowel disease, modulation of nitric oxide pathways. World J Gastroenterol 2020, 26(24):3365-3400.

56. Yang X, Pan Y, Xu X, Tong T, Yu S, Zhao Y, Lin L, Liu J, Zhang D, Li C: Sialidase Deficiency in Porphyromonas gingivalis Increases IL-12 Secretion in Stimulated Macrophages Through Regulation of CR3, IncRNA GAS5 and miR-21. Front Cell Infect Microbiol 2018, 8:100.

57. Siwicki M, Gort-Freitas NA, Messemaker M, Bill R, Gungabeesoon J, Engblom C, Zilionis R, Garris C, Gerhard GM, Kohl A et al: Resident Kupffer cells and neutrophils drive liver toxicity in cancer immunotherapy. Sci Immunol 2021, 6(61).

58. Shapouri-Moghaddam A, Mohammadian S, Vazini H, Taghadosi M, Esmaeili SA, Mardani F, Seifi B, Mohammadi A, Afshari JT, Sahebkar A: Macrophage plasticity, polarization, and function in health and disease. $J$ CELL PHYSIOL 2018, 233(9):6425-6440.

59. Xu X, Lu Y, Zhou L, He M, Zhuo J, Zhong Q, Luo K, Lin J: Tuning osteoporotic macrophage responses to favour regeneration by $\mathrm{Cu}$-bearing titanium alloy in Porphyromonas gingivalis lipopolysaccharide-induced microenvironments. Regen Biomater 2021, 8(1):a45.

60. Ohyama Y, Ito J, Kitano VJ, Shimada J, Hakeda Y: The polymethoxy flavonoid sudachitin suppresses inflammatory bone destruction by directly inhibiting osteoclastogenesis due to reduced ROS production and MAPK activation in osteoclast precursors. PLOS ONE 2018, 13(1):e191192.

61. Zhu WQ, Ming PP, Zhang SM, Qiu J: Role of MAPK/JNK signaling pathway on the regulation of biological behaviors of MC3T3 - E1 osteoblasts under titanium ion exposure. MOL MED REP 2020, 22(6):4792-4800. 
A

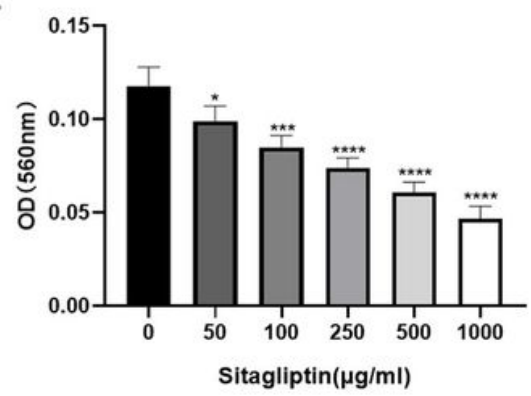

D

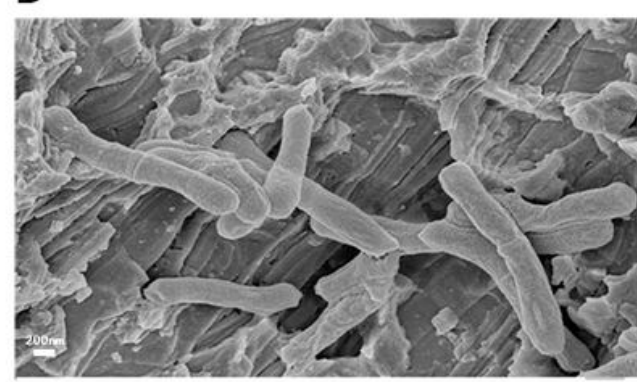

B

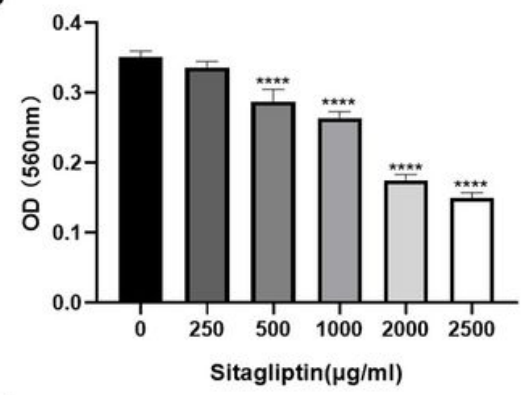

E

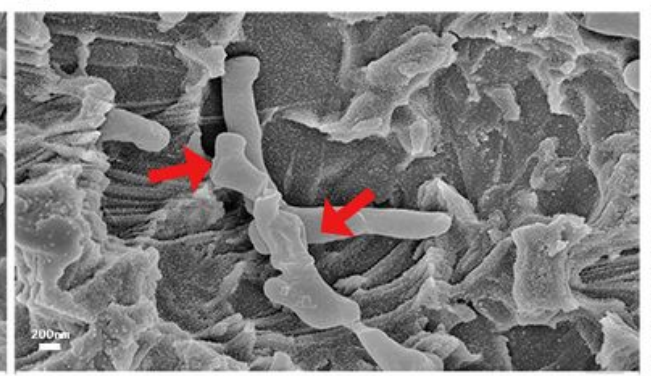

C

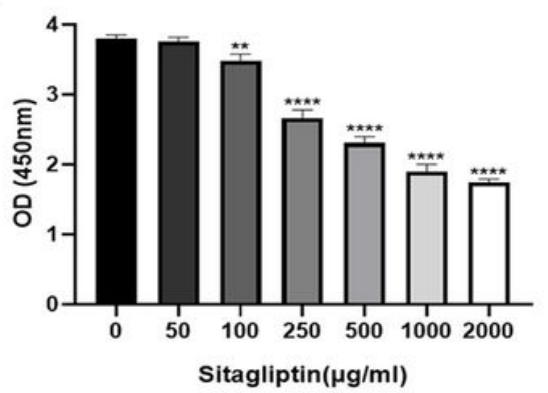

$\mathbf{F}$

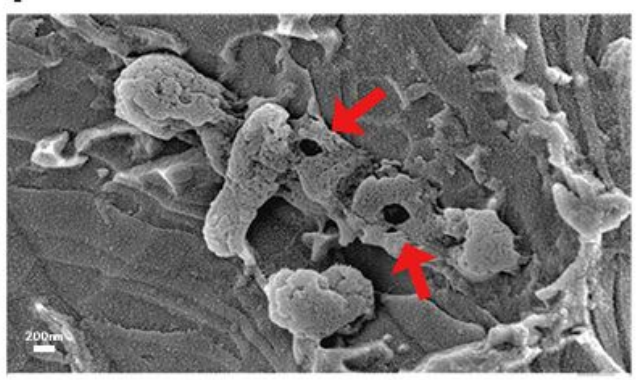

\section{Figure 1}

Antibiofilm activity of sitagliptin and morphological changes of P. gingivalis. (A)After $48 \mathrm{~h}$ of incubation with different concentrations of sitagliptin, a crystal violet staining assay was conducted and the OD560 value were recorded. (B) Mature biofilm was treated with sitagliptin for $24 \mathrm{~h}$ followed by a crystal violet staining assay and recordation of OD560 value. (C) Mature biofilm was incubated with sitagliptin for $24 \mathrm{~h}$ followed by a CCK8 assay and recordation of OD450 value. Data from three independent experiments

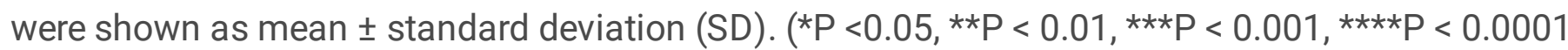
compared with P. gingivalis incubated without sitagliptin). (D-F) Morphological changes of P. gingivalis were observed by SEM. (D) Cells observed in the control group were plump and cell membranes remained clearly intact. (E) Treated with sitagliptin of MIC, cell membrane was shrunken (red arrows). (F) Treated with sitagliptin of MBC, perforation of cell membrane (red arrows) was observed and the cell structures were totally ruptured. 


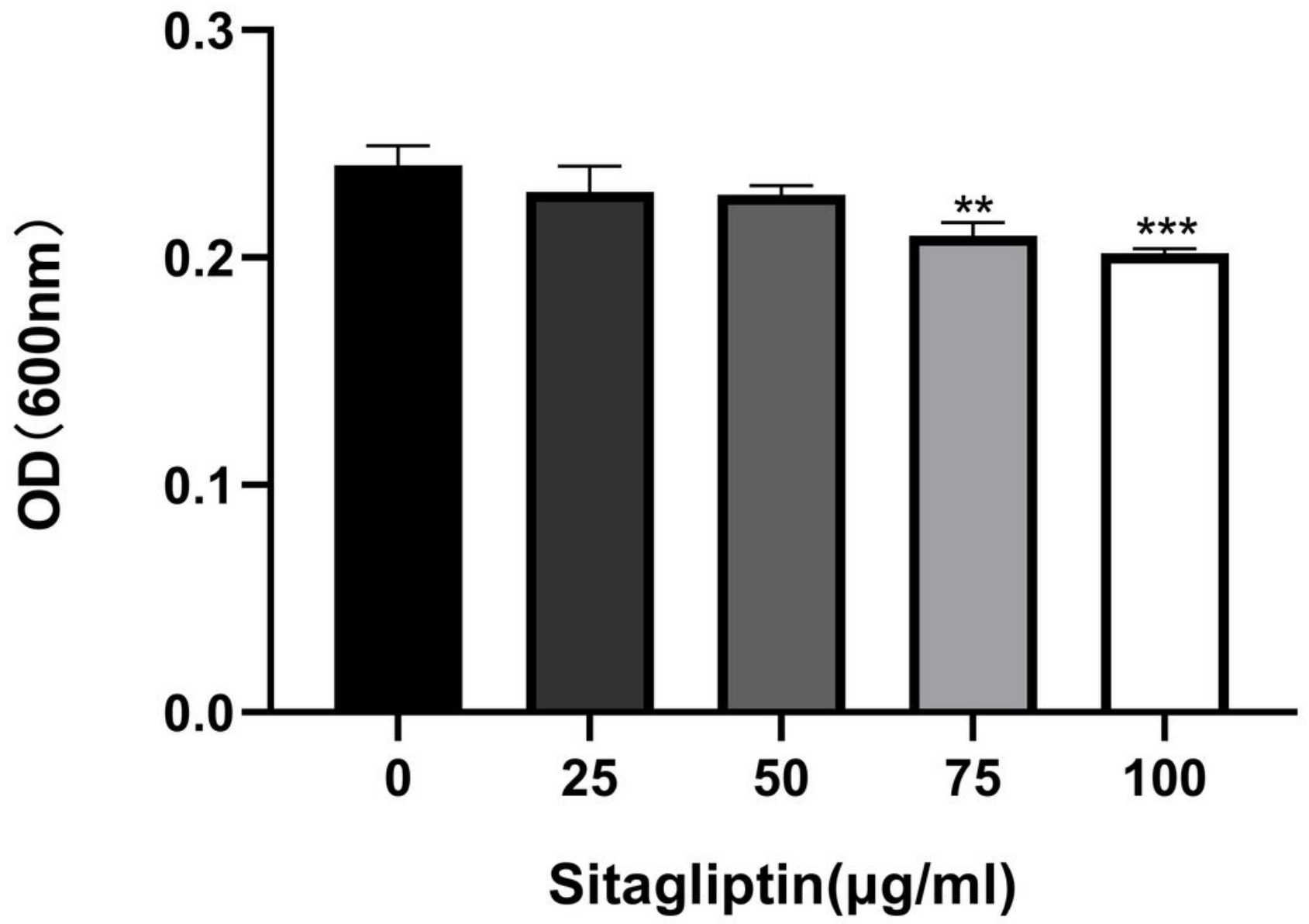

Figure 2

Effect of sitagliptin at sub-MIC on P. gingivalis growth. Following 48-hour incubation, the OD600 value of P. gingivalis suspension without or with sitagliptin of sub-MIC was measured. Data were expressed as mean $\pm S D .{ }^{\star *} P<0.01,{ }^{\star \star \star} P<0.001$ compared with $P$. gingivalis incubated without sitagliptin. 

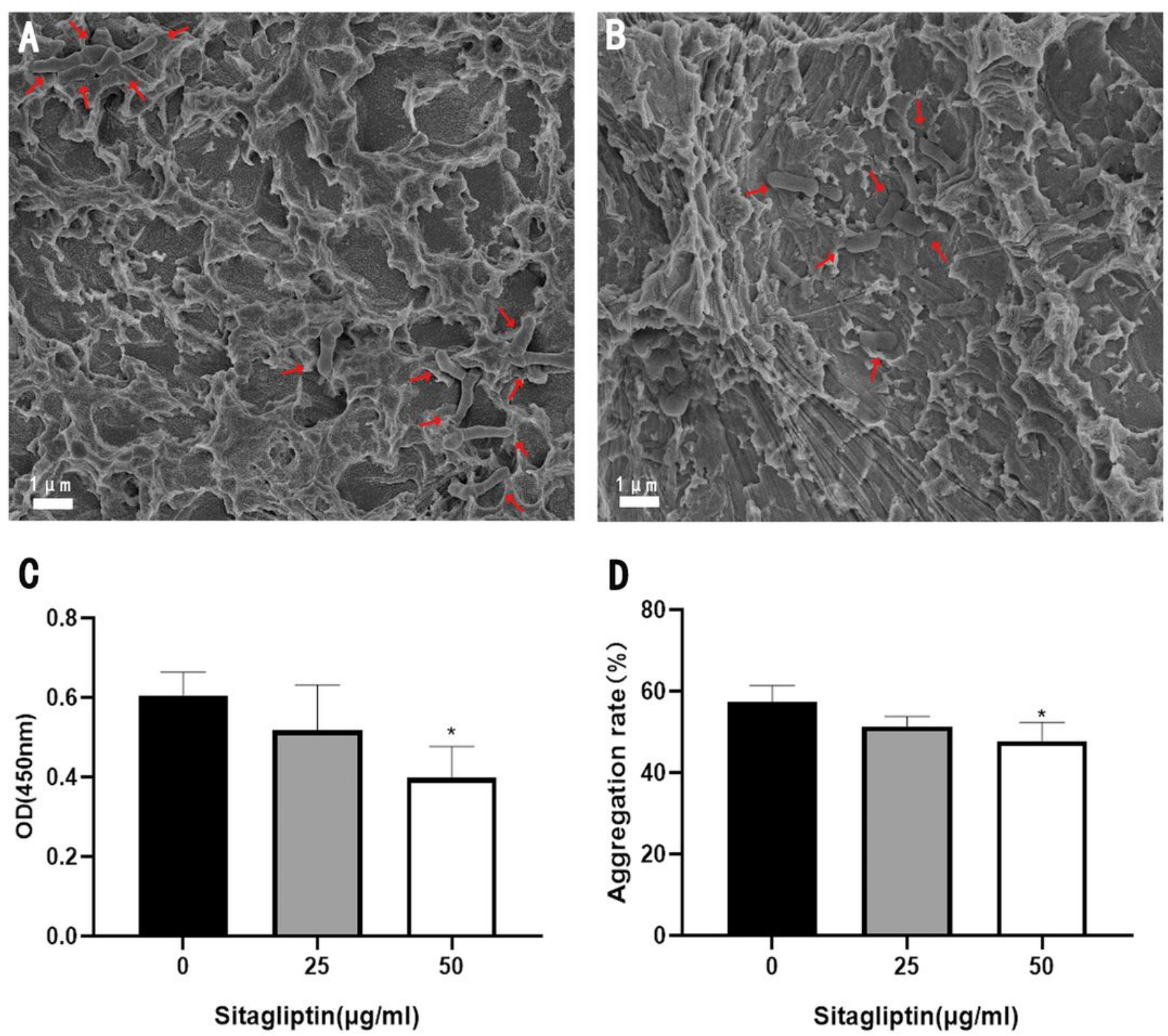

Figure 3

Effect of sitagliptin at sub-MIC on P. gingivalis early adhesion and aggregation. $(A, B)$ The SLA discs were immersed in P. gingivalis suspension with 0,25 and $50 \mu \mathrm{g} / \mathrm{ml}$ of sitagliptin and then incubated for $4 \mathrm{~h}$ anaerobically. The early adhered P. gingivalis (red arrows) to SLA discs was visually observed by SEM. (A)In the untreated group, more P. gingivalis cells observed adhered to the SLA discs and clumped together, (B)while fewer cells adhered to the discs and distributed separately in the treatment with sitagliptin of $50 \mu \mathrm{g} / \mathrm{ml}$. (C)A CCK8 assay was performed and data were shown as mean \pm SD. (D)P. gingivalis were incubated with sitagliptin of sub-MIC overnight anaerobically. Harvested by centrifugation, the bacteria were rinsed and re-suspended.The $0 D 600 \mathrm{~nm}$ value of the suspension was recorded after $3 \mathrm{~h}$. The percentage of aggregation was calculated by the following equation: Aggregation rate $=$ (ODInitial OD3h) / ODInitial $\times 100 \%$. ${ }^{*}<0.05,{ }^{*} \mathrm{P}<0.01$ compared with $\mathrm{P}$. gingivalis incubated without sitagliptin. 

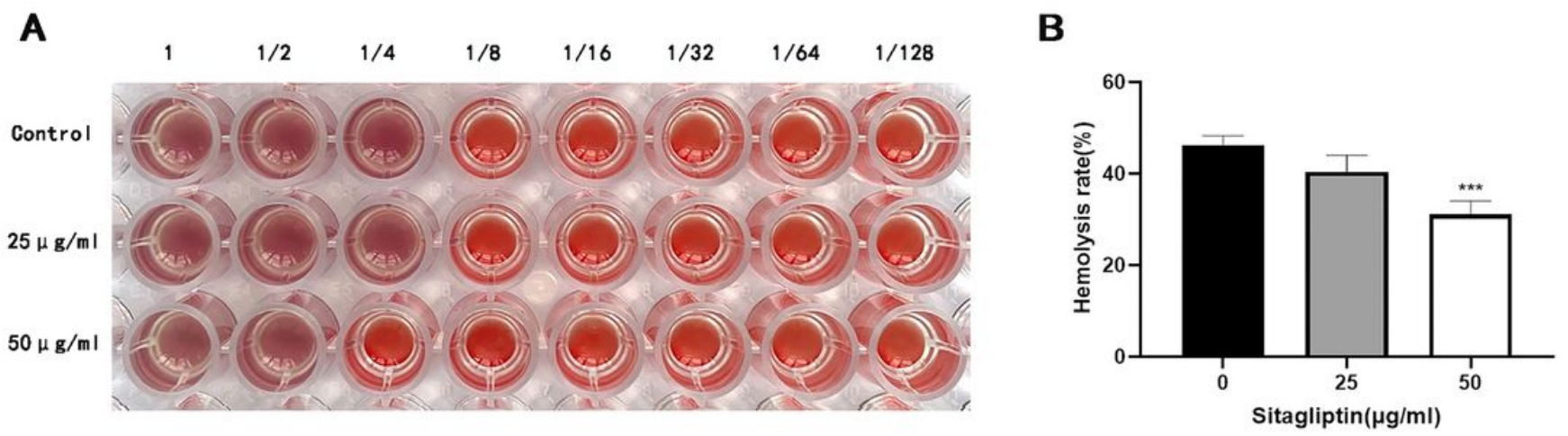

Figure 4

Effect of sitagliptin at sub-MIC on bacterial hemagglutination and hemolysis.(A) Overnight cultures of P. gingivalis with sitagliptin were harvested, centrifuged, and re-suspended. The bacteria suspension were serially diluted and mixed with sitagliptin of sub-MIC and erythrocytes suspension. After incubation for 3h, hemagglutination was detected visibly. (B) After washing and diluting, sheep erythrocytes were added in bacteria suspension with or without sitagliptin. The OD540 value was recorded. ${ }^{* \star *} \mathrm{P}<0.001$ compared with P. gingivalis incubated without sitagliptin. 


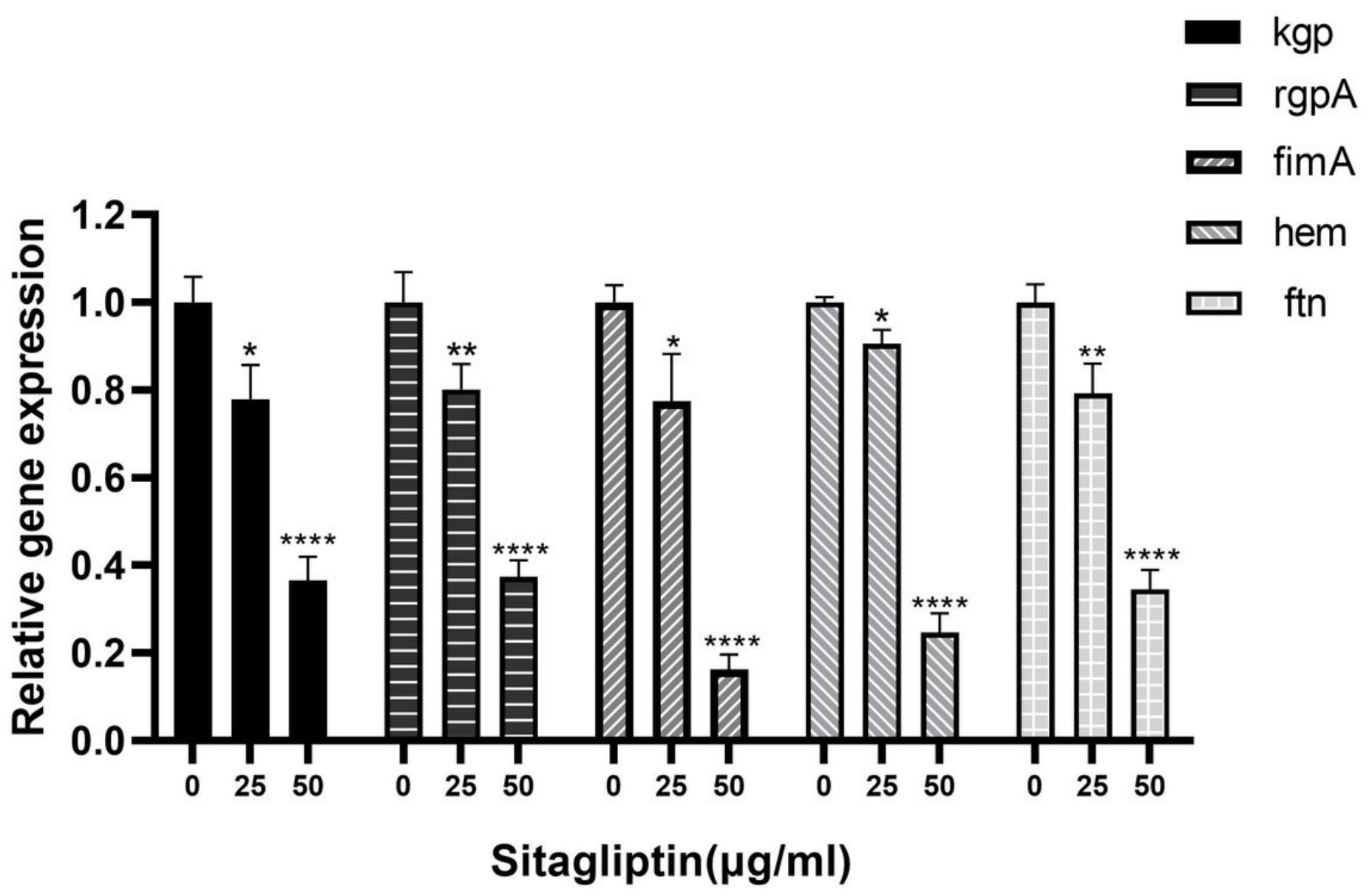

Figure 5

Effect of sitagliptin at sub-MIC on the expressions of virulence factors. The sitagliptin of sub-MIC was added to bacterial cultures $(\mathrm{OD} 600=0.8)$ prior to anaerobic culturing at $37^{\circ} \mathrm{C}$ for $24 \mathrm{~h}$. Transcriptional levels of the virulence genes of $P$. gingivalis were detected by real time-PCR. ${ }^{*} P<0.05,{ }^{\star \star} P<0.01,{ }^{\star}{ }^{*} \mathrm{P}<$ $0.001, * \star \star \star P<0.0001$ compared with P. gingivalis incubated without sitagliptin.

A

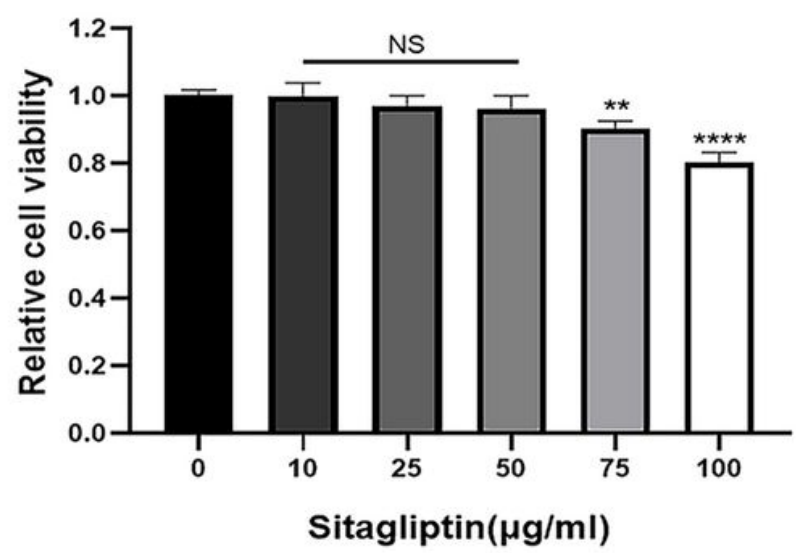

B

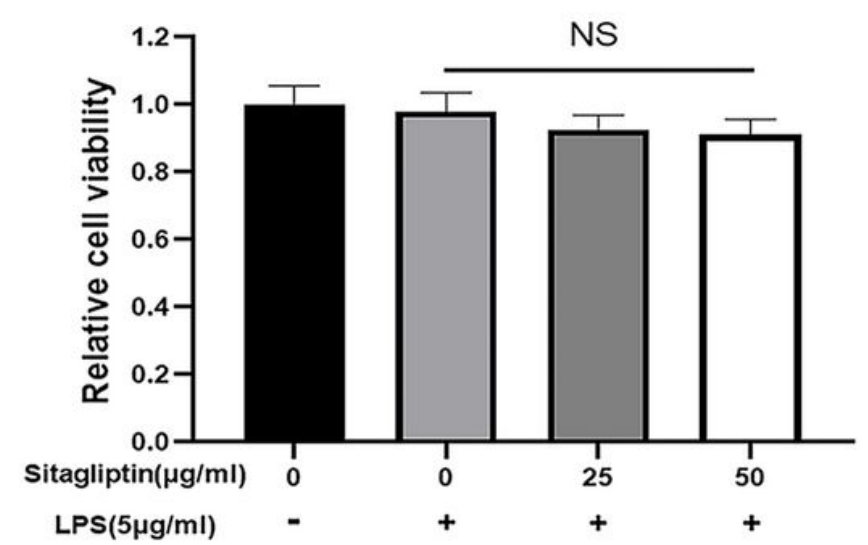

Figure 6 
Cytotoxicity assay.(A) Viability of cells treated with different concentrations of sitagliptin and (B) with sitagliptin in the absence or presence of Pg-LPS of $5 \mu \mathrm{g} / \mathrm{ml}$ for $24 \mathrm{~h}$ was detected by CCK8 ${ }^{\star \star *} \mathrm{P}<0.01$, $\star \star * * \mathrm{P}<0.0001$ compared with untreated group.

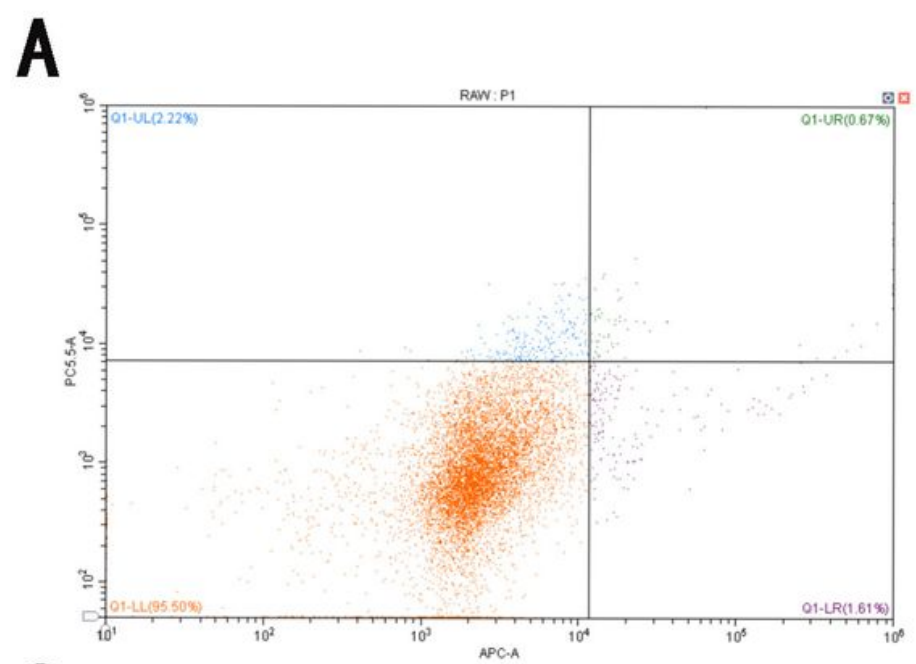

B
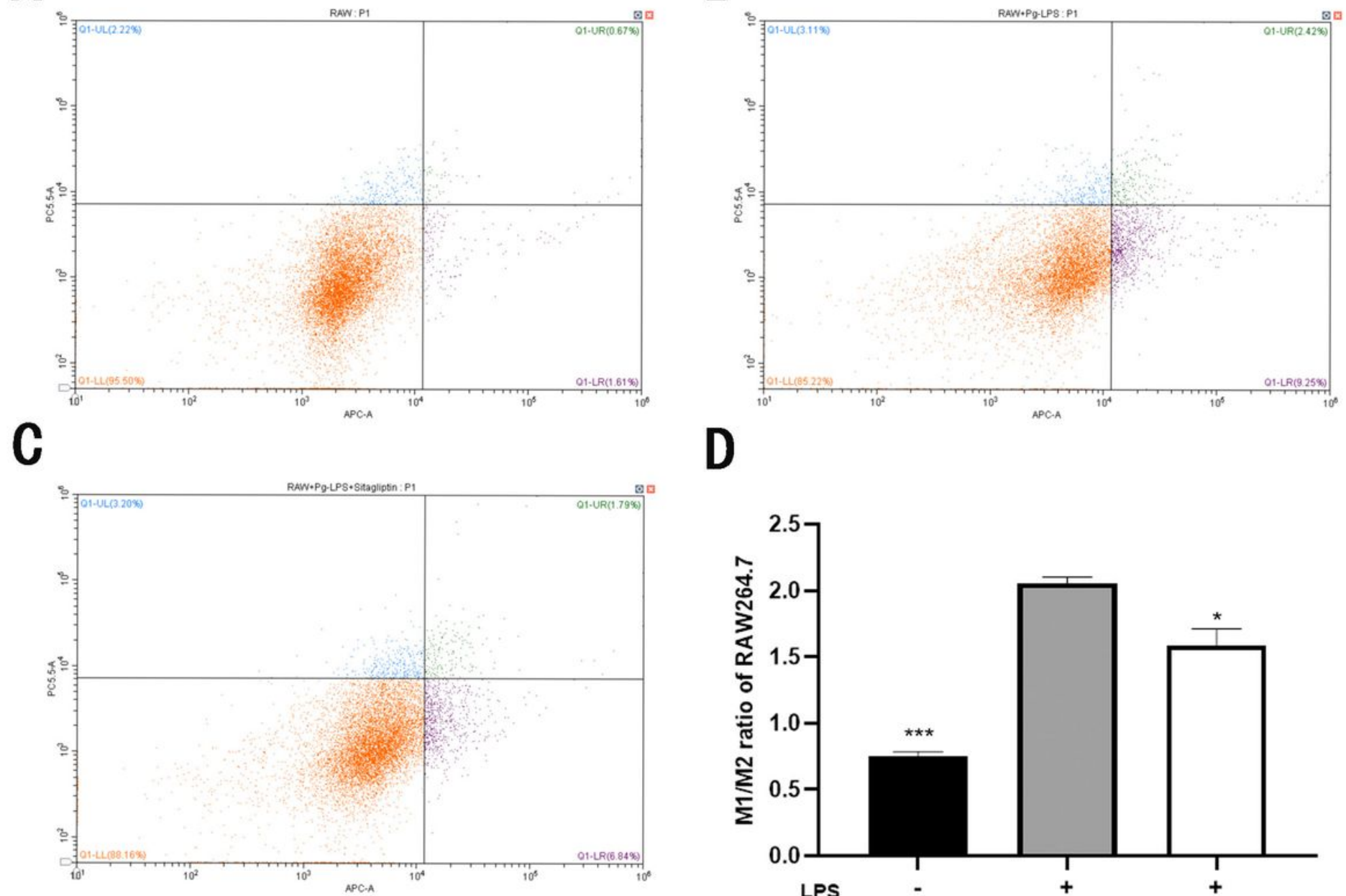

D

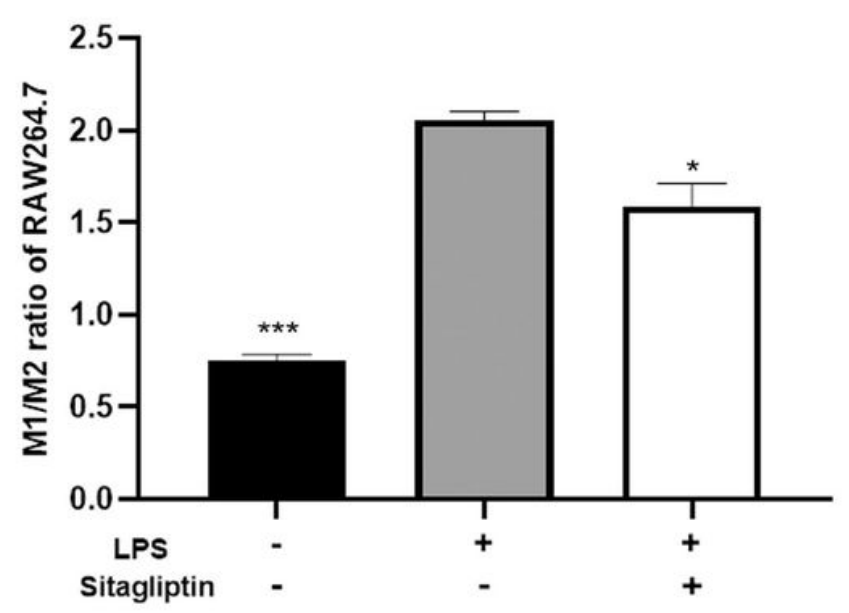

Figure 7

Protective effect of sitagliptin on macrophages polarization. (A) Flow cytometry assay of macrophages polarization of the untreated group; (B) flow cytometry assay of macrophages polarization of the treatment with $5 \mu \mathrm{g} / \mathrm{ml}$ of Pg-LPS®(C) flow cytometry assay of macrophages polarization of the treatment with $5 \mu \mathrm{g} / \mathrm{ml}$ of Pg-LPS and $50 \mu \mathrm{g} / \mathrm{ml}$ of sitagliptin; (D) analysis of the ratio of M1/M2. Data were expressed as mean \pm SD. ${ }^{*} \mathrm{P}<0.05$ and ${ }^{*} * \mathrm{P}<0.001$ compared with cells treated with Pg-LPS. 
A

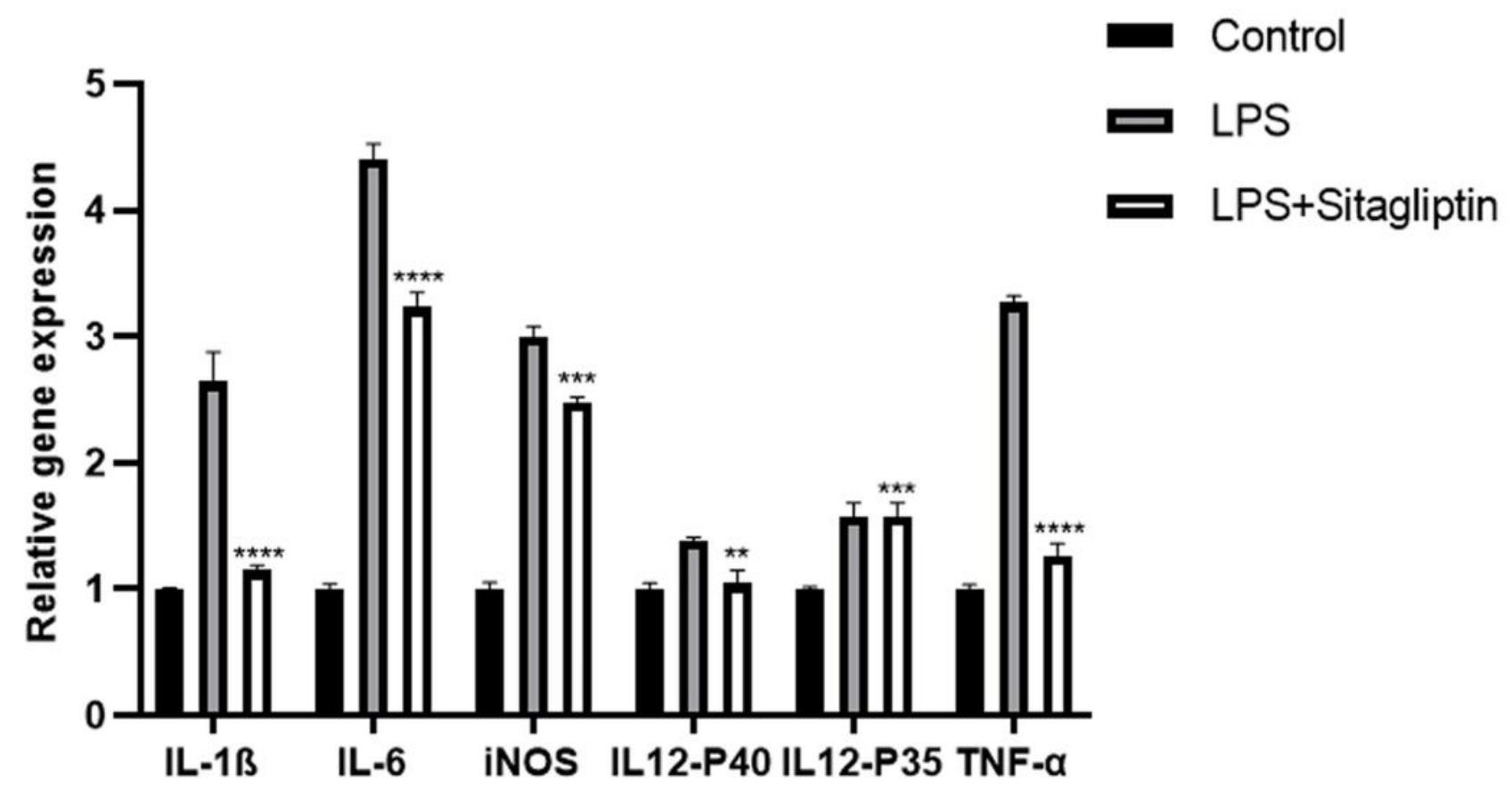

B
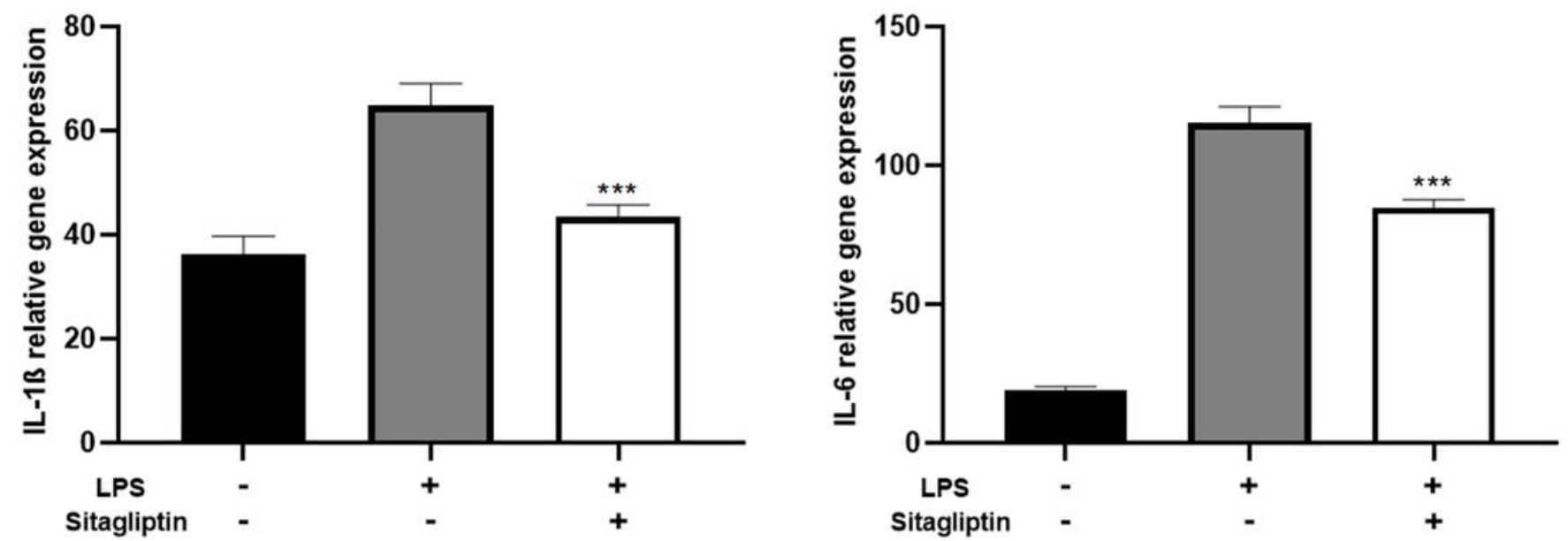

Figure 8

Sitagliptin attenuates the expression of inflammation-related cytokine in response to P. gingivalis LPS. (A) Relative levels of IL-1 $\beta$, IL-6, TNF-a, iNOS, IL12-P35 and IL12-P40 mRNA determined by qPCR. (B) Proteins levels of IL-1 $\beta$ and (C) IL- 6 in supernatants measured by ELISA. $(B, C)$ Data were expressed as mean \pm SD. ${ }^{\star} \mathrm{P}<0.05,{ }^{\star *} \mathrm{P}<0.01$ and ${ }^{\star \star *} \mathrm{P}<0.001$ compared with cells treated with Pg-LPS. 
A

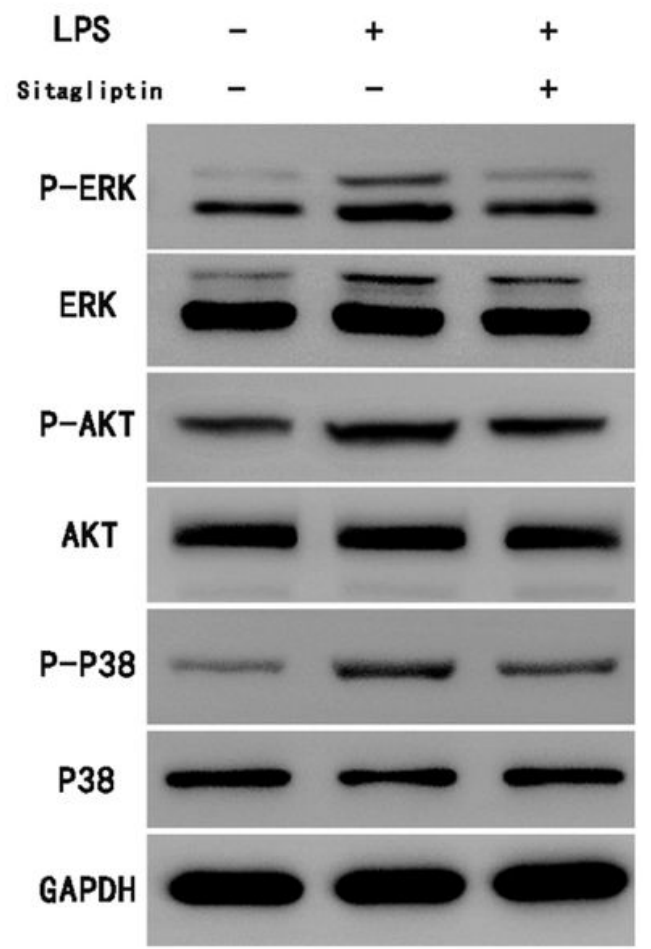

B

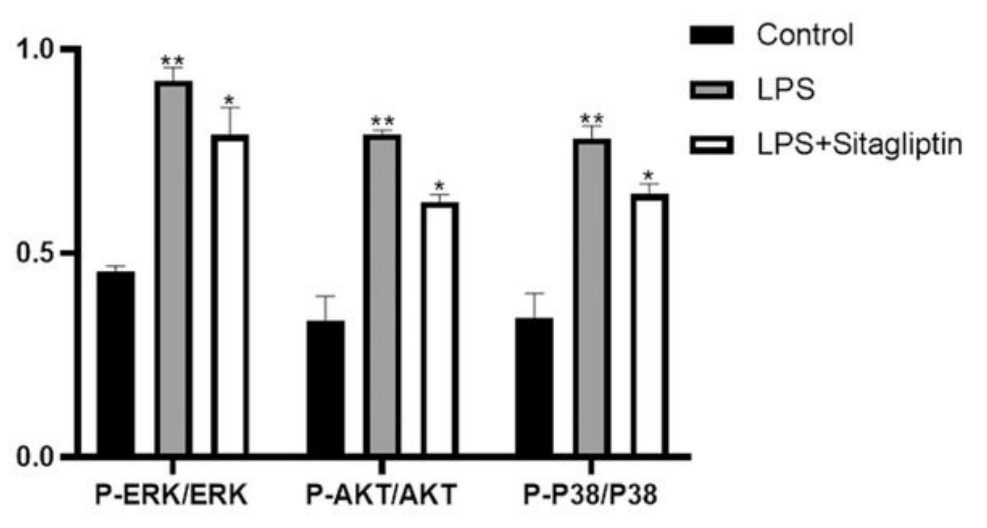

\section{Figure 9}

Sitagliptin Inhibits Activation of MAPK and AKT Signaling Pathways. RAW264.7 cells were treated with or without $50 \mu \mathrm{g} / \mathrm{ml}$ of sitagliptin in the absence or presence of $5 \mu \mathrm{g} / \mathrm{ml}$ of Pg-LPS. (A) Cell lysates were subjected to Western blot analysis. (B) The band intensities were quantified by Image $\mathrm{J}$ analysis. Data were expressed as mean \pm SD. * $p<0.05$ compared with treatment with Pg-LPS. ${ }^{*} p<0.05$ compared with Group1. 